\title{
La imagen del inmigrante en materiales de Comunicación Institucional Intercultural para la Salud
}

MHCJ no 7 | Año 2016

Artículo no 3 (75)

Páginas 53 a 85

mhjournal.org
Dra. Elsa María Moreda Sánchez | elsamoreda@gmail.com Universidad Rey Juan Carlos

Dra. Esther Martínez Pastor | esther.martinez.pastor@urjc.es Universidad Rey Juan Carlos

Dr. Ricardo Vizcaíno Pérez | ricardo.vizcaino@urjc.es Universidad Rey Juan Carlos
Palabras clave

Administración Pública; Comunicación; Inmigración; Institucional; Intercultural; Salud

Sumario

1. Introducción. 2. Metodología. 2.1. Delimitación del universo o población de análisis. 2.1.1. Límite temporal. 2.1.2. Límite geográfico. 2.1.3 Rastreo sistemático. 2.2. Variables de análisis. 3. Resultados. 3.1. Personajes. 3.2. Inmigrantes. 3.3. Estereotipos. 4. Discusión. 4.1. Personajes. 4.2. Inmigrantes. 4.3. Estereotipos. 5. Conclusiones. 6. Bibliografía. 7. Notas

\section{Resumen}

Existe una línea de investigación fundamental hasta ahora poco desarrollada en España: la Comunicación Institucional Intercultural para la Salud. Es incipiente puesto que no es hasta el año 2000 cuando en España la Administración Pública se establece como "sujeto comunicante" en materia intercultural. El hecho de que la Administración Pública se establezca como nuevo actor en este sistema es, sin duda, muy importante, y no sólo para la salud individual de los nuevos ciudadanos y ciudadanas, sino para la salud colectiva de la población, en definitiva, para la Salud Pública. En este trabajo se propone analizar la imagen del inmigrante en los materiales de Comunicación Institucional Intercultural para la Salud. A partir de un análisis de contenido de los materiales, se confirma el escaso recurso a las imágenes reales de personas como medio para representar una diversidad de orígenes. No obstante, cuando representadas, sí se encuentra cierta coherencia en género, edad y profesión con las características de los inmigrantes en España. Se concluye, en definitiva, que en general las campañas y materiales de Comunicación Institucional para la Salud dirigidos a inmigrantes analizados no adaptan culturalmente sus imágenes. Pese a lo incipiente de esta investigación, supone un importante avance en el interés por sistematizar la evaluación de la Comunicación Institucional Intercultural para la Salud (CIIS) que se lleva cabo.

\section{Forma de citar este artículo en las bibliografías}

Elsa María Moreda Sánchez , Esther Martínez Pastor, Ricardo Vizcaíno Pérez (2016): “ La imagen del inmigrante en materiales de Comunicación Institucional Intercultural para la Salud”, en Miguel Hernández Communication Journal, nº7, páginas 53 a 85. Universidad Miguel Hernández, UMH (Elche-Alicante). Recuperado el__ de de

20__ de: [link del artículo en mhjournal.org] 


\title{
Immigrants' image on Public Administrations' Intercultural Health Communication materials
}

MHCJ n으 7 | Año 2016

Artículo no 3 (75)

Páginas 53 a 85

mhjournal.org

\author{
Dra. Elsa María Moreda Sánchez | elsamoreda@gmail.com \\ Universidad Rey Juan Carlos \\ Dra. Esther Martínez Pastor | esther.martinez.pastor@urjc.es \\ Universidad Rey Juan Carlos \\ Dr. Ricardo Vizcaíno Pérez | ricardo.vizcaino@urjc.es \\ Universidad Rey Juan Carlos
}

Keywords

Public Administration; Communication; Immigrants; Institutional; Intercultural; Health

Summary

1. Introduction. 2. Methodology. 2.1. Delimitation of the sample universe. 2.1.1. Time limit. 2.1.2. Geographical limit. 2.1.3. Systematic search. 2.2. Variables. 3. Results. 3.1. Characters. 3.2. Immigrants. 3.3. Stereotypes. 4. Discussion. 4.1. Characters. 4.2. Immigrants. 4.3. Stereotypes. 5. Conclusions. 6. Bibliography. 7. Notes.

\begin{abstract}
There exists a fundamental area of investigation currently not sufficiently developed in Spain: Public Administrations' Intercultural Health Communication. It is incipient as it is only in the year 2000 when in Spain Public Administrations start to develop intercultural communications. The fact of the Public Administration being a new actor in the system is, without any doubt, very important, not only for the individual health of the persons to whom the new communications are aimed at, but also to Public Health. It is the purpose of this work to analyze the image of the immigrants in the Public Administrations' Intercultural Health Communication materials. By the means of a content analysis of the materials, a lack of representation of persons from a diversity of origins is found. Nevertheless, when persons of a diversity of origins are included, gender, age and profession features represent the general characteristics of the immigrant population in Spain.
\end{abstract} Therefore, it is concluded that, in general, materials do not include culturally adapted images. Even though this investigation is only very incipient, it represents an important step towards the evaluation of the Public Administrations' Intercultural Health Communication.

\section{How to cite this paper in bibliographies}

Elsa María Moreda Sánchez, Esther Martínez Pastor, Ricardo Vizcaíno Pérez (2016): “ La imagen del inmigrante en materiales de Comunicación Institucional Intercultural para la Salud”, en Miguel Hernández Communication Journal, $\mathrm{n}^{\circ} 7$, páginas 53 a 85. Universidad Miguel Hernández, UMH (Elche-Alicante). Recuperado el _ de de 20__ de: [link del artículo en mhjournal.org] 


\section{Introducción}

Si se toma como punto de partida que según datos del Instituto Nacional de Estadística (INE) la población residente en España a 1 de Enero de 2011 superaba la cifra de 47 millones de personas y, que de ese total, algo más de 5,7 millones eran de nacionalidad extranjera, se encuentra que un 12,2\% de las personas que residían en nuestro país a 1 de Enero de 2011 tenían una nacionalidad distinta a la española. Este dato contrasta bruscamente con el escaso 2,28\% que registraba el INE a 1 de enero de 2000 y refleja, a primera vista, cómo la sociedad española se transformó, en tan sólo una década, en una sociedad multicultural (Martínez Pastor, 2009:148), caracterizada, tal como apuntó Martínez Pastor (2009: 148) siguiendo a Alsina (1997: 14), por una "coexistencia de distintas culturas en un mismo espacio mediático o virtual"1.

La investigación en comunicación durante el mismo periodo 2000-2010 tuvo entonces que desarrollarse teniendo en cuenta la nueva situación. No obstante, la mayoría de los estudios sobre comunicación intercultural y más concretamente sobre publicidad e inmigración en España se centraron principalmente en una perspectiva mercantilista, muchos de ellos motivados en su mayoría por la iniciativa privada, que buscaba en un nuevo target un nicho rentable de mercado (Baladrón, 2009: 102; Martínez Pastor y Vizcaíno-Laorga, 2008: 2). Mientras tanto, los campos de la comunicación institucional, comunicación social y comunicación para la salud, cuando abordados, obviaron, en la inmensa mayoría de las ocasiones, y salvo ciertas excepciones que se expone a lo largo de este trabajo, la perspectiva de la inmigración.

La falta de investigación en este campo, no se justifica, sin embargo, por su falta de oportunidad. Los inmigrantes se convirtieron, durante esta primera década del siglo XXI, en un colectivo fundamental. Por poner un ejemplo, el Plan Multisectorial frente a la infección por VIH y el Sida 2001-2005 impulsado por el Ministerio de Sanidad, puso ya entonces de relieve la importancia de este colectivo en la prevención de la transmisión, al reconocer que la "precariedad legal, socio-económica, laboral y familiar puede hacer aumentar la vulnerabilidad" (Ministerio de Sanidad y Consumo, 2001: 30). Para ello se plantearon una serie de objetivos, entre ellos "continuar desarrollando campañas de prevención de VIH/SIDA dirigidas a inmigrantes en diferentes idiomas y ampliar a otros idiomas y otros medios de difusión" (Ministerio de Sanidad y Consumo, 2001: 37).

El Plan Multisectorial 2008-2012 fue más allá, reconociendo, en su presentación, que "las estrategias contra el VIH están estrechamente relacionadas con el refuerzo de los valores europeos sobre protección de los derechos humanos, incluidos los derechos sobre sexualidad y reproducción, los derechos de las minorías y los derechos fundamentales de los inmigrantes" (Ministerio de Sanidad y Consumo, 2008: 6).

Esto resume la importancia de la Comunicación Institucional Intercultural ${ }^{2}$ en materia sanitaria e implica, por tanto, a responsables a nivel institucional de la gestión de la salud pública. Lo que se plantea aquí es reforzar la investigación de la comunicación para la salud desde una perspectiva que tenga en cuenta la diversidad cultural presente.

Es por tanto, una investigación a caballo entre la comunicación institucional, intercultural y para la salud. Conviene destacar, especialmente, esta última. La comunicación para la salud comprende el estudio y la 
utilización de la comunicación estratégica para influir en la salud individual y colectiva de las poblaciones y cómo ésta puede contribuir a la prevención de enfermedades y la promoción de la salud (U.S. Department of Health and Human Services, 2010). La situación de la investigación sobre comunicación y salud en España al inicio de esta investigación se caracterizaba por su dispersión (Ugarte, 2008: 44), tan sólo señalar que es el 1 de enero de 2011 cuando se lanza el primer número de la Revista Comunicación y Salud, con el objetivo principal de unificar, en una publicación científica, los avances en este campo en España e Iberoamérica (Ugarte, 2011: 1).

De nuevo, este panorama no se justifica, no obstante, por su falta de pertinencia. La utilización de distintos tipos de comunicación (comunicación interpersonal, grupal, comunitaria, masiva...) puede asegurar que todas las personas accedan, procesen y comprendan la información sobre la salud que facilite la toma de decisiones que repercutan en una promoción de la salud y prevención de las enfermedades.

De hecho, las desigualdades en el acceso a información, servicios y tecnología en el ámbito de la salud pueden traer consigo una utilización inferior de los servicios de prevención, menor conocimiento sobre el seguimiento y control de las enfermedades crónicas, mayores tasas de hospitalización y un peor estado de salud percibido (Berkman, 2004). Mejorar la comunicación puede significar, además, una mayor equidad en el acceso a los servicios sanitarios (Thiede, 2008: 1171) y, en definitiva, una reducción de las desigualdades sociales en salud (Borrell et al., 2012).

Por ello, al desarrollo de la investigación en nuestro país sobre comunicación institucional (García López, 2001; Cortés González, 2011; y otros) y comunicación-publicidad intercultural (Arroyo, 2009; Baladrón, 2009; y otros), no sólo deben añadirse las incipientes investigaciones sobre comunicación institucional intercultural (Martínez Pastor,Gaona Pisonero y Vizcaíno Laoraga, 2008; y otros), información-comunicación para la salud (Cuesta, Ugarte y Menéndez, 2006; y otros), y comunicación interpersonal intercultural para la salud (Valero, 2013; Sales, 2006; y otros); sino que es necesario añadir y reforzar la investigación en lo que en este trabajo se ha llamado Comunicación Institucional Intercultural para la Salud, como disciplina incipiente.

Se plantea, por tanto, una línea de investigación fundamental hasta ahora poco desarrollada. Es incipiente puesto que, a pesar de que el origen del estudio de la comunicación intercultural se remonta a los años 50 del siglo XX en Estados Unidos, no es hasta el año 2000 cuando, en España, la Administración Pública se establece como "sujeto comunicante" en materia intercultural (Martínez Pastor, Gaona Pisonero, Vizcaíno-Laorga, 2008: 13).

Por ello, a pesar de que en España existiera ya desde la última década del siglo XX un interés por parte de la Administración de desarrollar la Comunicación Institucional, no es hasta la primera década del siglo XXI cuando ésta se abre a la diversidad cultural ahora presente. Es el objetivo de la comunicación intercultural conocer los intercambios comunicativos que se establecen entre diferentes sistemas socioculturales o entre diferentes subsistemas dentro del mismo sistema sociocultural. El hecho de que la Administración Pública se establezca como nuevo actor en este sistema le obliga, por una parte, a 
estar en constante diálogo con los diferentes grupos culturales constitutivos de la sociedad y, al mismo tiempo, construir un diálogo común, mediante políticas de integración (Martínez Pastor, Gaona Pisonero, Vizcaíno-Laorga, 2008: 13-14).

En el caso específico de la comunicación para la salud, este papel como nuevo actor es, sin duda, muy importante, y no sólo para la salud individual de los nuevos ciudadanos y ciudadanas, sino para la salud colectiva de la población, en definitiva, para la Salud Pública.

Es oportuno, por tanto, teniendo en cuenta el contexto en el que nace esta investigación, delimitar como objetivo general para este trabajo analizar la imagen del inmigrante en los materiales de Comunicación Institucional Intercultural para la Salud. El objetivo se concreta en un análisis de la adaptación cultural de las imágenes contenidas en las campañas y materiales elaborados por la Administración, puesto que se trabaja con la siguiente hipótesis de partida: "Las campañas y materiales de Comunicación Institucional para la Salud dirigidas a inmigrantes no incluyen de manera generalizada representaciones de personas de una diversidad de orígenes".

\section{Metodología}

Puesto que el objetivo general busca específicamente analizar la imagen del inmigrante en la Comunicación Institucional Intercultural para la Salud, la presente investigación se centra en un análisis de contenido de las campañas y materiales recopilados.

Es el análisis de contenido la técnica de investigación seleccionada, puesto que se trata de aquella técnica que destaca entre los estudios de comunicación. Se entiende como técnica de investigación el procedimiento metodológico según el cual se accede a la realidad, obteniendo así los datos siguiendo los preceptos estandarizados por la literatura científica (Martínez Nicolás, 2011: 18).

El análisis de contenido puede definirse como el conjunto de procedimientos interpretativos de productos comunicativos (mensajes, textos o discursos) que proceden de procesos singulares de comunicación previamente registrados, y que, basados en técnicas de medida, a veces cuantitativas (estadísticas basadas en el recuento de unidades), a veces cualitativas (lógicas basadas en la combinación de categorías) tienen por objeto elaborar y procesar datos relevantes sobre las condiciones mismas en que se han producido aquellos textos, o sobre las condiciones que puedan darse para su empleo posterior (Piñuel Raigada, 2002: 2).

Tal y como señaló Bardin (1986: 32), corresponden al campo del análisis de contenido las actividades en las que, partiendo de un conjunto de técnicas parciales pero complementarias, consisten en explicitar y sistematizar el contenido de los mensajes y la expresión de ese contenido con la ayuda de indicios cuantificables o no. Todo ello con la finalidad de efectuar deducciones lógicas y justificables concernientes a la fuente (el emisor y su contexto) o, eventualmente, a los efectos de los mensajes tomados en consideración. 
Según Bardin (1986: 23), además, no existen plantillas ya confeccionadas y listas para ser usadas, simplemente se cuenta con algunos patrones base, a veces difícilmente traspasables, por lo que la técnica del análisis de contenido adecuada al campo y al objetivo perseguidos, es necesario inventarla, o casi.

Se parte, por tanto, en esta investigación, de una selección de modelos de análisis de materiales publicados en la literatura a partir de los cuales se elabora una ficha de análisis de contenido propia adaptada al contexto específico de trabajo.

\subsection{Delimitación del universo o población de análisis}

Teniendo en cuenta que el objetivo general se concreta en un análisis de la adaptación cultural de las imágenes contenidas en las campañas y materiales elaborados por la Administración, el Universo se compone por todas aquellas campañas y materiales de Comunicación Institucional para la Salud dirigidas a inmigrantes por las Administraciones relevantes. Con el propósito de hacer operativo este objetivo, se establecen los límites que se exponen a continuación.

\subsubsection{Límite temporal}

El límite temporal cubre el período 2000-2010, puesto que se puede considerar el inicio del siglo XXI como punto de inflexión por varias razones, pero especialmente:

- Por el inicio de un período de crecimiento sostenido de la inmigración,

- Por la aprobación de La Ley Orgánica 4/2000, de 11 de enero, sobre derechos y libertades de los extranjeros en España y su integración social, que extiende el acceso a la asistencia sanitaria pública a todos los inmigrantes empadronados.

De la misma forma, el análisis termina a finales de 2010, fecha en la que se constata una ralentización en la llegada de inmigrantes a España. Esta investigación permite, por tanto, un estudio de todos los materiales elaborados durante una década que estuvo caracterizada por el crecimiento sostenido de la llegada de inmigrantes a nuestro país.

\subsubsection{Límite geográfico}

Considerando que el objetivo específico remite a aquellas Administraciones Públicas con competencias en la gestión del Sistema Nacional de Salud, y que este se configura, tal y como establece el Ministerio de Sanidad, como el conjunto coordinado de los servicios de salud de la Administración del Estado y los servicios de salud de las Comunidades Autónomas (Ministerio de Sanidad, 2012: 6), se encuentra, por extensión, un Universo que abarca toda la geografía nacional. 
Existe, efectivamente, cierta problemática resultante del límite geográfico de esta investigación, puesto que remite a un amplio límite espacial o geográfico. Cabe señalar que recopilar las campañas y materiales editados por la Administración Central y Autonómica sobre cuestiones de salud dirigidos a la población inmigrante es una tarea compleja, toda vez que remite a un fenómeno extenso que remite a toda la geografía nacional. Esta extensión exige una búsqueda de información dispersa y no siempre disponible. Todo ello obliga a plantear una metodología ad hoc basada en una combinación de estrategias dependiendo del tipo de información y de la fuente. La metodología utilizada en el rastreo sistemático de las fuentes seleccionadas se detalla a continuación.

\subsubsection{Rastreo sistemático}

Partiendo de una exploración inicial realizada durante la primera etapa de trabajo de campo de la tesis doctoral de la primera autora y que dio cuenta de la disponibilidad de materiales y fuentes, se realizó un rastreo sistemático con el objetivo de buscar, identificar y recopilar todos los materiales y campañas disponibles y editados en toda la geografía nacional tanto por la Administración central como por la Administración autonómica, entre el 1 de enero de 2000 y el 31 de diciembre de 2010, que tratasen temas relacionados con la salud, y que estuviesen dirigidos a inmigrantes.

La búsqueda sistemática y recopilación se realizó acudiendo a las siguientes fuentes primarias:

- Administración Central (denominaciones ministeriales según el Real Decreto 1313/2010, de 20 de octubre, por el que se reestructuran los departamentos ministeriales):

- Ministerio de Sanidad, Política Social e Igualdad

- Ministerio de Trabajo e Inmigración

- Instituto/Consejo de la Juventud

- Administración Autonómica:

- Consejerías de Salud/Sanidad

- Consejerías de Bienestar/Asuntos Sociales

- Consejerías de Igualdad/Institutos de la Mujer

- Consejerías de Trabajo/Institutos para la prevención de Riesgos Laborales

- Consejerías de Inmigración

- Consejerías/Institutos de la Juventud

La búsqueda sistemática a través de las fuentes primarias se realizó acudiendo a los centros de documentación, bibliotecas, catálogos de publicaciones y páginas web oficiales de la Administración; así como a través de los contactos personales presenciales, telefónicos y por correo electrónico con las Administraciones.

Además, se acudió a centros de documentación y bibliotecas, así como a bibliografías y referencias en documentos y materiales de especial interés como fuentes secundarias. 
El resultado de la búsqueda en todas las fuentes rastreadas sumó un total de 471 campañas y materiales. No obstante, pese a que se parte con 471 campañas y materiales como Universo a analizar, un reconocimiento inicial puso de manifiesto la existencia de un número muy amplio de entradas dobles, errores y materiales de imprecisa procedencia o elaboración en el corpus inicial. Además, muchos de los materiales estaban dirigidos a la población general y no estaban traducidos a ningún idioma extranjero, encontrándose únicamente disponibles en español o incluso en algún idioma autonómico. Teniendo en cuenta la situación, se procedió a la depuración del corpus con los siguientes criterios de inclusión:

- Campañas y materiales editados por la Administración Central o Autonómica.

- En este sentido, se excluyeron tanto los materiales editados por otro tipo de entidades (ONG, asociaciones, etc.) con el apoyo económico o subvención de la Administración; como los materiales editados por otras instituciones provinciales y locales.

- Esta exclusión es importante puesto que el análisis principal se centra en la Comunicación Institucional, entendida como punto de partida, como aquella puesta en marcha por la propia Administración. Además, por un criterio de coherencia y uniformidad, se excluyeron los materiales cuya iniciativa partía de una institución distinta a la Central o Autonómica, tales como juntas provinciales y hospitales.

- Dirigidos específicamente a la población inmigrante.

- Solo se tuvieron en cuenta los dirigidos a la población general cuando estaban traducidos a algún idioma extranjero. En los casos que no existía traducción, sólo se incluyeron aquellos que apelaban directamente al colectivo inmigrante, bien por mención expresa en el texto o en la imagen.

- El tema central de la campaña o material debía estar relacionado con cuestiones de salud.

- En este sentido, se incluyeron aquellos cuyo objetivo era informar sobre el acceso a los servicios sanitarios, aquellos relacionados con la salud y seguridad laboral y aquellos relacionados con la prevención de la violencia de género.

- Se excluyeron, por otra parte, materiales editados en forma de diccionario u hoja de entrevista, por no ser su objetivo la comunicación y/o educación para la salud.

- $\quad$ Editados entre enero de 2000 y diciembre de 2010.

Finalmente, se agruparon 155 materiales y campañas. Todos ellos cumplen los siguientes criterios:

- Fueron elaborados (y no sólo financiados) por la Administración Central o Autonómica.

- Tenían como público objetivo la población inmigrante y/o estaban traducidos, al menos, a un idioma extranjero.

- El tema central estaba relacionado con cuestiones de salud.

- $\quad$ Fueron difundidas entre enero de 2000 y diciembre de 2010.

\subsection{Variables de análisis}

Tal y como se señala anteriormente, es característico de la técnica de análisis de contenido que no existan plantillas ya confeccionadas y listas para ser usadas, sino que simplemente se cuente con algunos patrones base, a veces difícilmente traspasables (Bardin, 1986: 23). 
Por tanto, se parte en esta investigación de una exploración de modelos de análisis de materiales publicados en la literatura a partir de los cuales se elabora una ficha de análisis de contenido propia adaptada al contexto específico de trabajo. En concreto se analiza las fichas de análisis de adaptación cultural de materiales para la salud de Masset (1996) y Guidry et al. (1996).

Tanto Masset (1996: 240) como Guidry et al. (1999: 296) desarrollaron sus modelos de análisis partiendo de la recomendación general de adaptar el elemento visual, imágenes y fotografías en los materiales dirigidos a minorías e incluyeron en sus modelos una serie de variables fundamentales para el análisis de estos elementos. Masset incluyó variables centradas en el análisis de la inclusión o no de imágenes, formato y representación de personas y contextos de otras culturas, entre otras. Masset propuso también el análisis de estereotipos y elementos ofensivos. Guidry et al. (1996) registraron información sobre el mensaje visual y las imágenes teniendo en cuenta la representación y apariencia física de personas, contextos, interacciones y roles, entre otros.

Además, otros autores que han analizado la adaptación cultural de intervenciones y materiales para la salud, como Weintraub et al. (2003: 279), señalaron específicamente que las imágenes deberían mostrar personas similares al público objetivo para alcanzar un mayor grado de adaptación. Liu et al. (2012: 91) incluyeron, así mismo, la utilización de personajes similares al público objetivo como una tipología de adaptación fundamental en las intervenciones.

Los elementos utilizados para el análisis de la adaptación cultural de las imágenes en los modelos de referencia sirvieron como base para la elaboración de un protocolo de análisis propio. Puesto que el objetivo general se centra en el análisis de la imagen del inmigrante en los materiales de Comunicación Institucional Intercultural para la Salud, se analizan, en primer lugar, el tipo de diseño de los materiales, es decir, si se incluyen imágenes o no en los materiales, lo que nos permite identificar aquellos sobre los que se centrar específicamente el análisis. A continuación se describe el sistema de categorías, descripción y codificación a aplicar en el análisis de contenido desarrollado. Teniendo en cuenta los objetivos marcados, se desarrollan tres variables fundamentales: personajes, inmigrantes, y estereotipos representados.

1. Personajes: en lo que se refiere al análisis de personajes, se analiza la existencia de personajes y en concreto, sobre el personaje o personajes principales, se analizan sus características en relación con el género, edad, profesión, origen, caracterización y rol.

2. Inmigrantes: de la misma manera, el análisis de los inmigrantes representados incluye la identificación de la representación o no de inmigrantes y en concreto, sobre el inmigrante o inmigrantes principales, se analiza además de sus características (género, edad, profesión, origen, caracterización y rol), si este coincide o no con el personaje principal del material.

3. Estereotipos: se entienden los estereotipos como aquellas ideas o conceptos estáticos, en este caso sobre colectivos o grupos determinados. Se identifica la existencia de estereotipos, su modo de representación y su referencia. 


\section{Resultados}

Se parte de una mayoría de materiales (146, un 94\%) que utilizan imágenes en su composición. A continuación se expone los resultados de las variables: personajes, inmigrantes y estereotipos.

\subsection{Personajes}

Respecto al análisis de los personajes se encuentra, en primer lugar, que la presencia de personajes en comparación con otros elementos es mayoritaria en las imágenes, pues se identifica un $81 \%$ de materiales (un total de 125) que incluyen imágenes que representan algún personaje.

Los personajes representados son en un $46 \%$ de ocasiones (57 materiales) de ambos géneros. Cuando se representa un único género se encuentra que la representación única femenina supera ligeramente la representación exclusiva del género masculino ( 33 o 26\% frente a 26 o 21\%). El siguiente gráfico muestra las proporciones encontradas en cada uno de los casos.

Gráfico 1. Género de los personajes representados

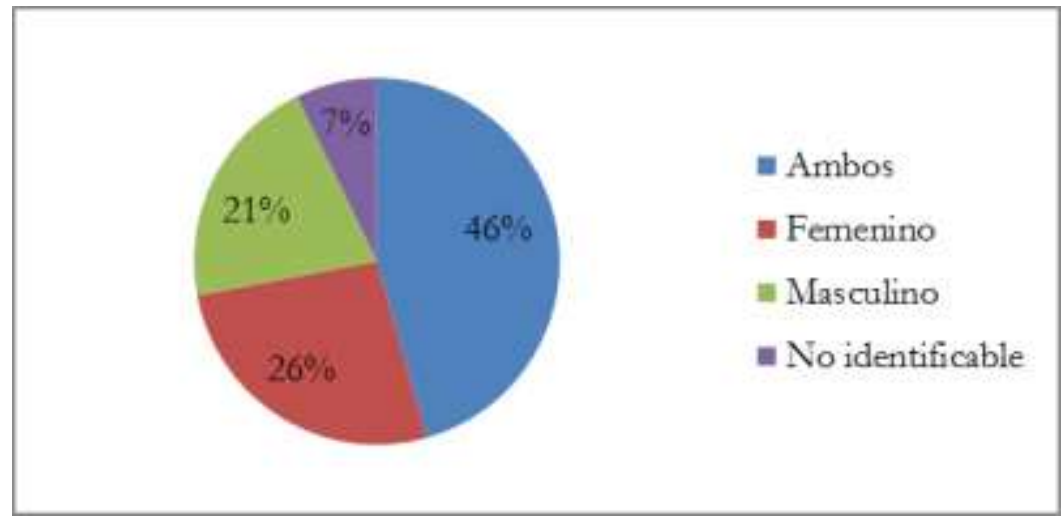

Fuente: Elaboración propia

En lo que se refiere a la edad, se encuentra sobre todo personajes jóvenes y/o adultos. Se identifican personajes maduros en 56 materiales (45\%) y jóvenes en $33(26 \%)$. Son $20(16 \%)$ los materiales que representan a la vez personajes jóvenes y maduros y 15 (12\%) los que representan personajes de todas las edades. 
Gráfico 2. Edad de los personajes representados

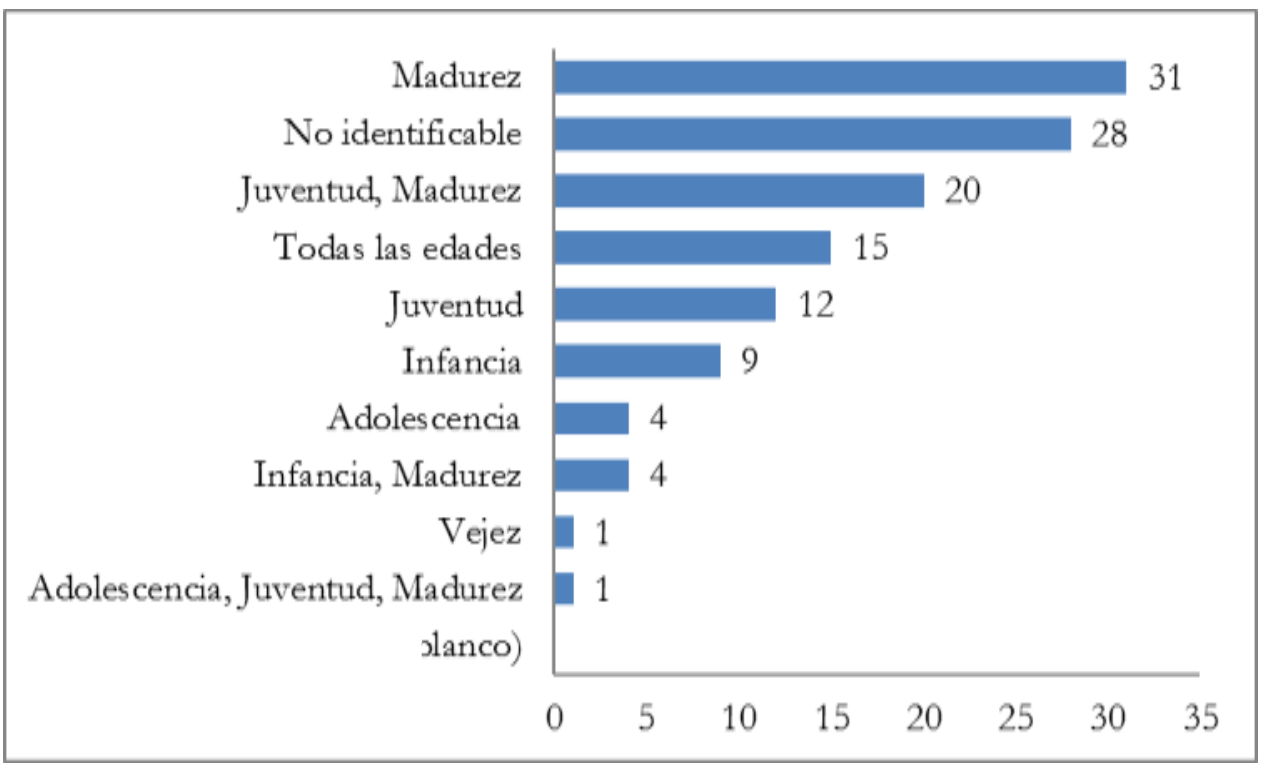

Fuente: Elaboración propia

Respecto a las profesiones representadas, cabe destacar que 83 materiales $(66 \%)$ no representan ninguna profesión. $35(24 \%)$ representan, no obstante, trabajos físicos. 6 materiales representan trabajos intelectuales y 4 profesiones sanitarias. 4 son también los materiales que representan varias profesiones a la vez.

Gráfico 3. Profesiones de los personajes representados

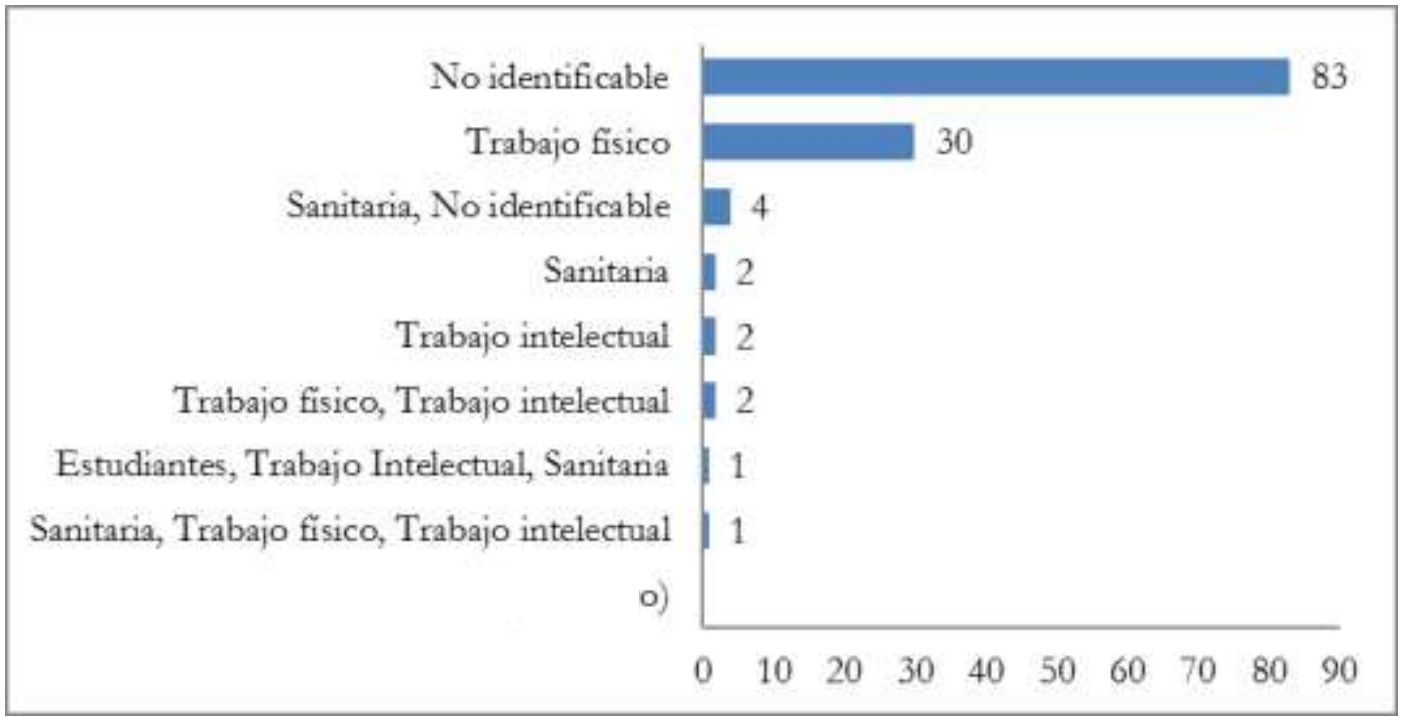

Fuente: Elaboración propia

En lo que se refiere al origen de las personas representadas en las imágenes, se encuentran 87 materiales $(70 \%)$ en los que no es posible identificar un origen concreto. Cuando se identifican orígenes distintos al autóctono, estos representan en la mayoría de las ocasiones un grupo culturalmente diverso (32 
materiales, un 26\%). Solo en 3 ocasiones se identifica un origen individualizado, correspondiente con una caracterización negra. En 2 ocasiones se identificó un origen claramente autóctono.

Gráfico 4. Origen de los personajes representado

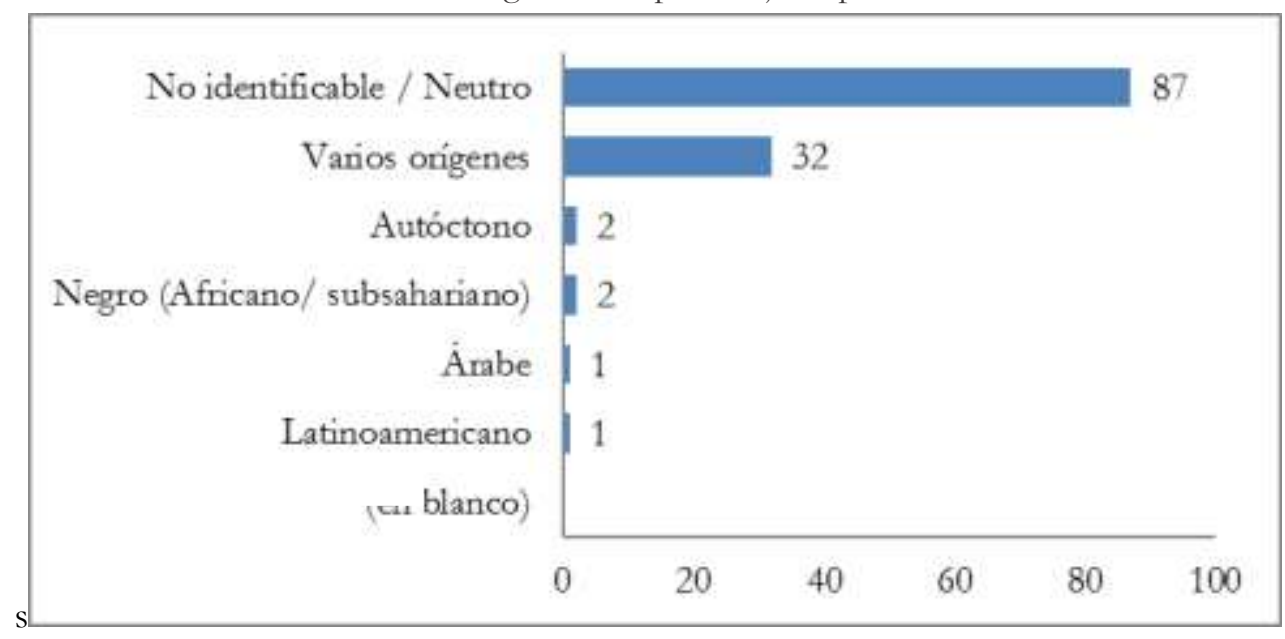

Fuente: Elaboración propia

La variable origen guarda estrecha relación con otra de las variables incluidas, y que se refiere a la caracterización de los personajes en la imagen. Cabe destacar que en la mayoría de las ocasiones (100, $80 \%$ ), la caracterización de los personajes se clasifica como occidentalizada o neutra, por el recurso a personajes de características prácticamente neutras junto con elementos únicamente de la cultura autóctona (vestimenta, peinados, etc.). La caracterización multicultural se encontró en imágenes en las que se recurría a personajes de distintos orígenes para apelar a la diversidad y, además, se recurría a un conjunto de elementos tales como el color de piel, peinado y/o accesorios de ropa de diversas culturas para representar lo diverso de su imagen. Se encontraron 23 materiales $(18 \%$ de los que representan algún personaje) clasificados de esta forma. 2 materiales apelaban a un grupo culturalmente específico, al menos desde el punto de vista de sus personajes y su caracterización.

Gráfico 5. Caracterización de los personajes representados

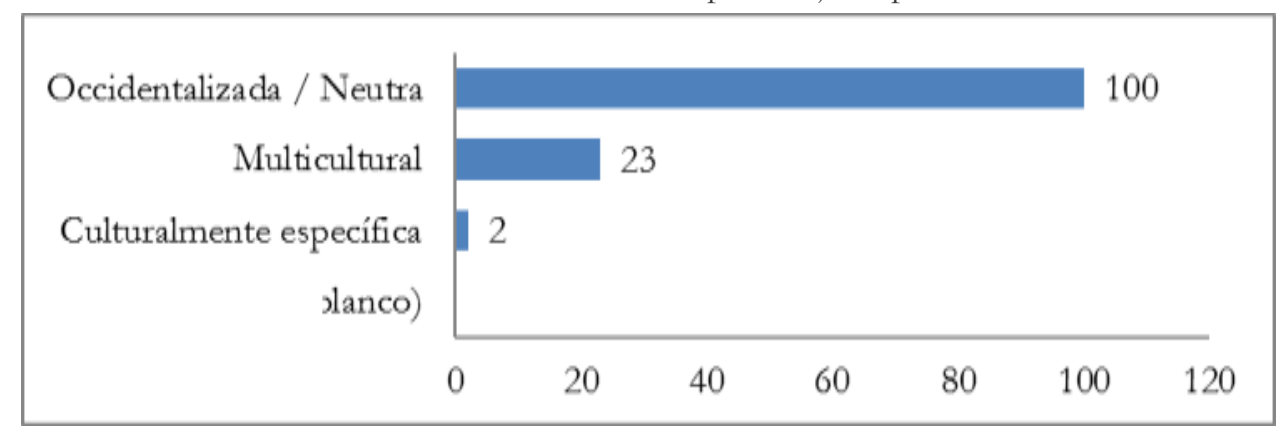

Fuente: Elaboración propia

Por último, respecto al papel y rol de los personajes principales en la imagen, se encuentra que 82 materiales $(66 \%)$ no otorgan ningún papel a los personajes. Cuando otorgado, este es frecuentemente activo (38 materiales, un 30\%). 
Gráfico 6. Papel de los personajes representados

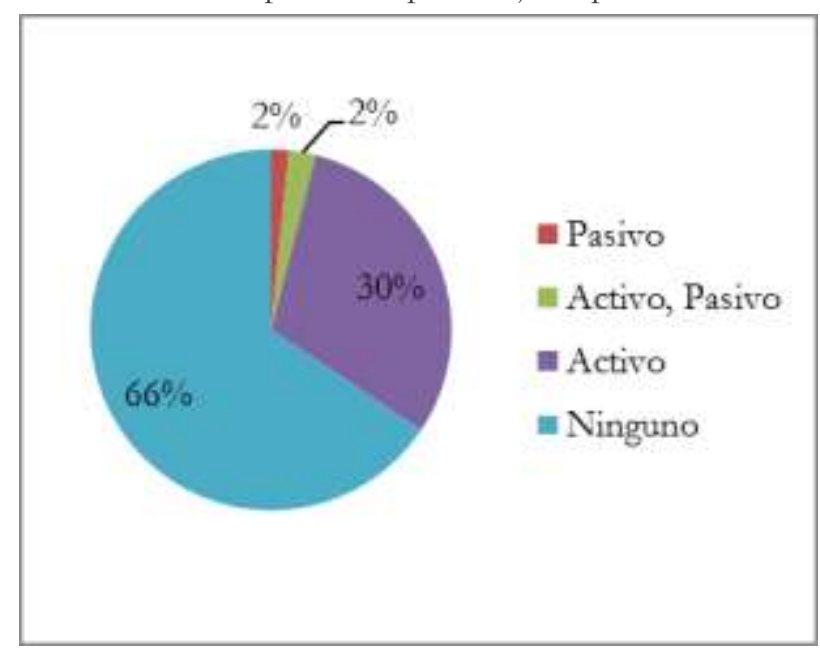

Fuente: Elaboración propia

Esta variable guarda relación con el rol asignado a los personajes. La falta de representación de una actividad por parte de los personajes se relaciona con el recurso al personaje como forma de representación del público objetivo. Se encuentra este rol en 116 materiales (93\%).

Gráfico 7. Rol de los personajes representados

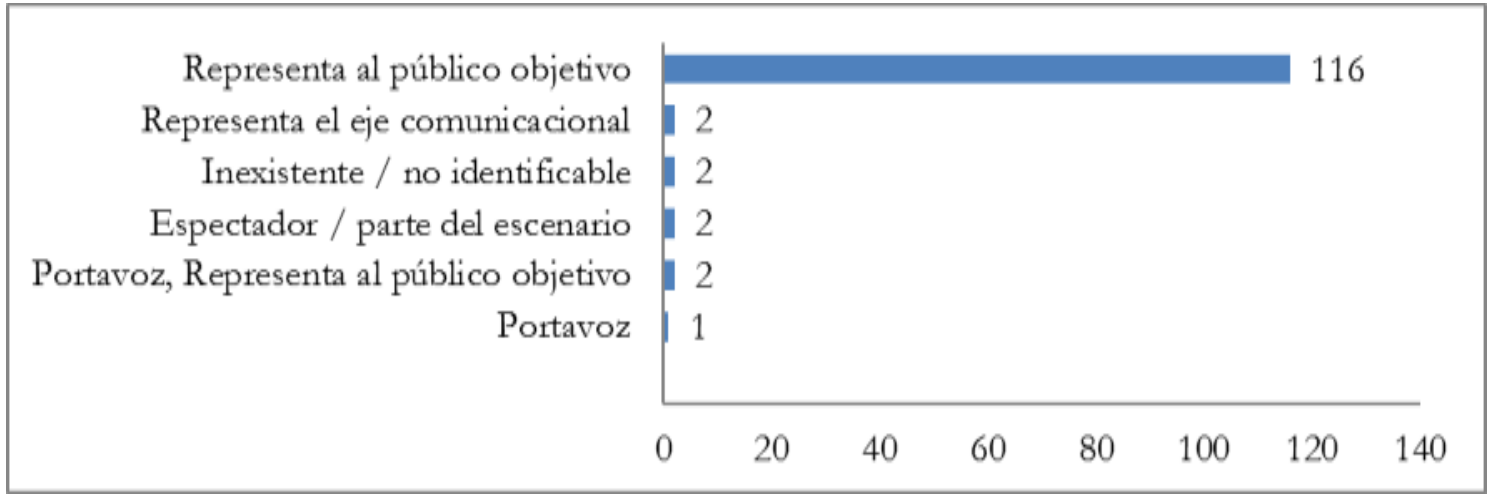

Fuente: Elaboración propia

\subsection{Inmigrantes}

Es interesante comparar los datos que se acaban de resumir sobre la imagen y personajes principales con el análisis específico de los inmigrantes representados.

Es relevante destacar que aunque existen una mayoría (81\%) de materiales que representan algún personaje, muchos de ellos (84 materiales, un 67\%) no representan personas de origen extranjero. 41 materiales (33\%) sí representan algún inmigrante. 
Gráfico 8. Existencia de inmigrante en la imagen

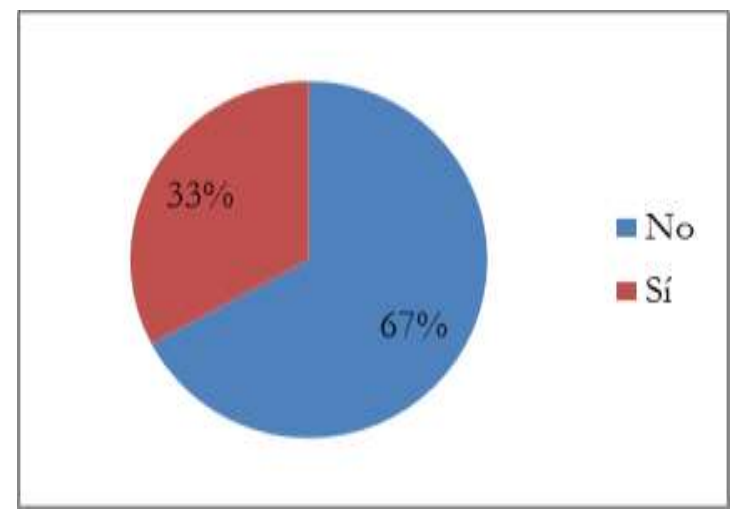

Fuente: Elaboración propia

No obstante, cuando se encuentran representaciones de personas inmigrantes, estas coinciden en la mayoría de las ocasiones con el personaje principal del material (35 materiales, un 85\%), como muestra la siguiente gráfica.

Gráfico 9. Coincidencia del inmigrante con el personaje principal

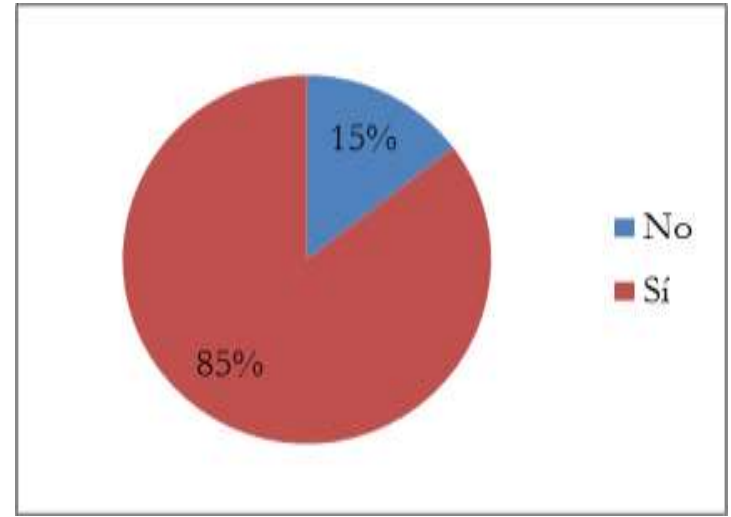

Fuente: Elaboración propia

Respecto a las características de los inmigrantes representados en las imágenes se encuentra, en línea con los resultados del análisis del público objetivo y del total de personajes representados, que la representación más abundante es la de inmigrantes de ambos géneros (21 materiales, un 51\%), y que cuando se representa un género de manera individualizada, los materiales que representan inmigrantes de género femenino (15 materiales, un 37\%) son más numerosos que los que representan únicamente inmigrantes de género masculino (5 materiales, un 12\%), tal y como muestra la gráfica siguiente. 
Gráfico 10. Género de los inmigrantes representados

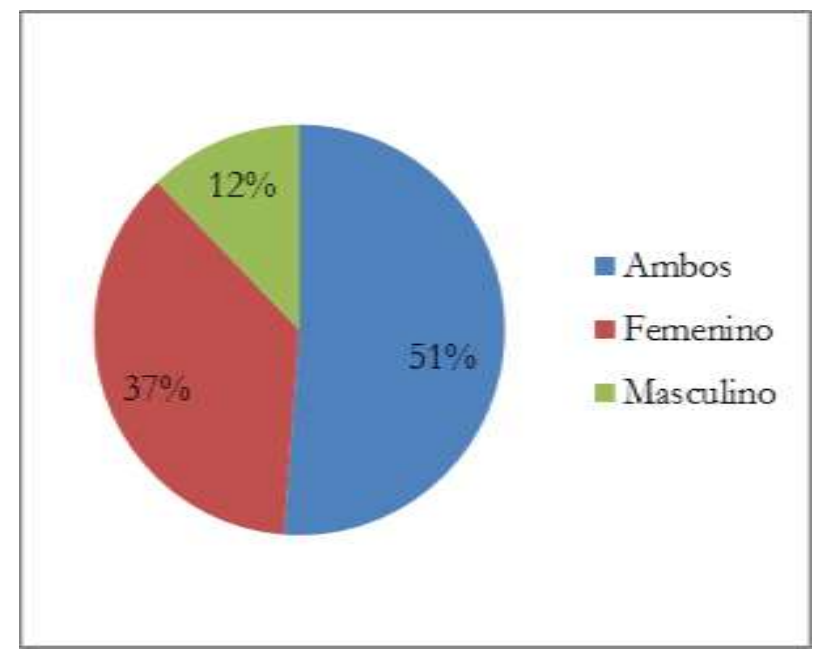

Fuente: Elaboración propia

En cuanto a las edades representadas, destacan, de nuevo, los inmigrantes jóvenes y adultos. Se identifican 19 materiales (46\% de los materiales que incluyen algún inmigrante en la imagen) que representan inmigrantes maduros y 18 (44\%) que representan inmigrantes jóvenes. 12 materiales (29\%) representan inmigrantes de todas las edades. El siguiente gráfico muestra las combinaciones de edades mostradas en los materiales.

Gráfico 11. Edad de los inmigrantes representados

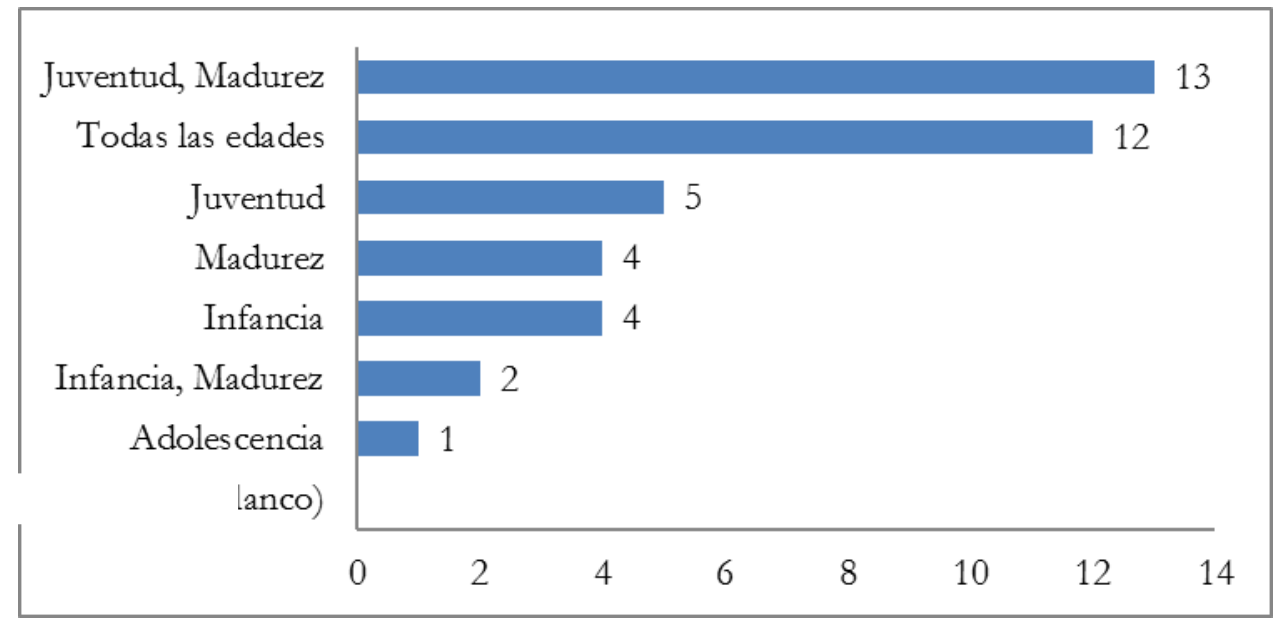

Fuente: Elaboración propia

En lo que se refiere a las profesiones representadas, destaca, nuevamente, la proporción de materiales (31, un 76\%) entre los que no es posible identificar ninguna profesión. Entre los materiales en los que sí es posible, se encuentran una representación mayoritaria de trabajos físicos, presentes en 9 materiales (90\% de los materiales que representan alguna profesión). 
Gráfico 12. Profesión de los inmigrantes representados

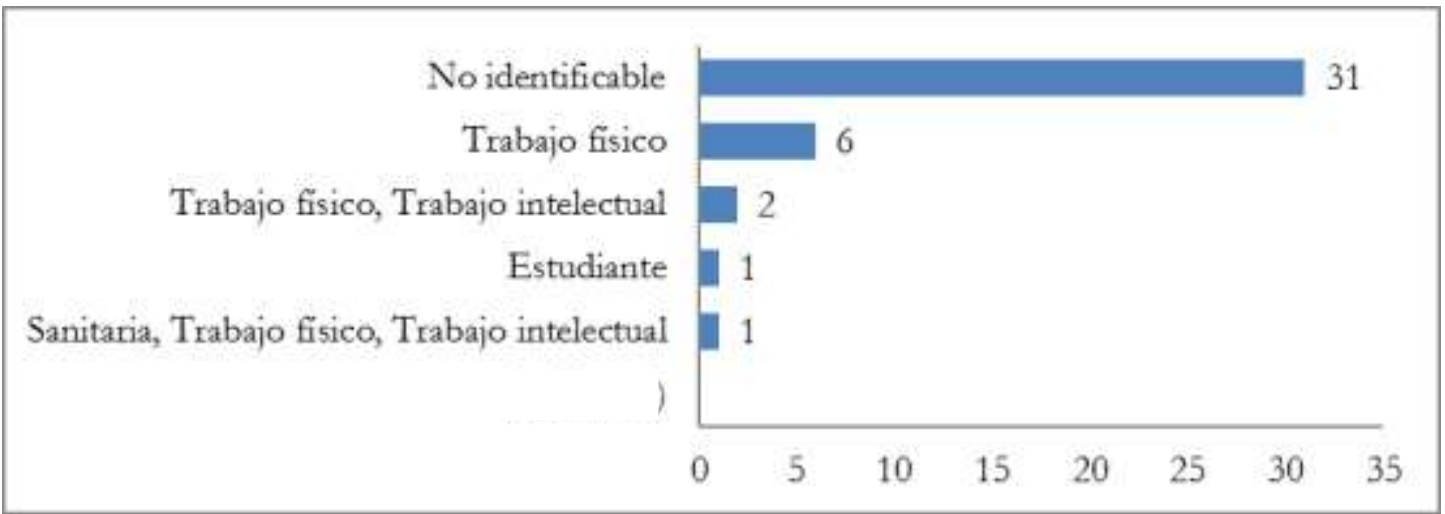

Fuente: Elaboración propia

En lo que respecta al origen, destaca que la mayoría de los materiales representan inmigrantes de varios orígenes (33 materiales, un 81\%). Cuando se representa un origen concreto, la representación comparativamente más abundante es la de personas con rasgos negro-africanos (4 materiales, un 10\%), seguidos de las personas de rasgos árabes (2 materiales, un 5\%). No obstante, el número absoluto de materiales de este tipo es relativamente pequeño, como se acaba de señalar.

Gráfico 13. Origen de los inmigrantes representados

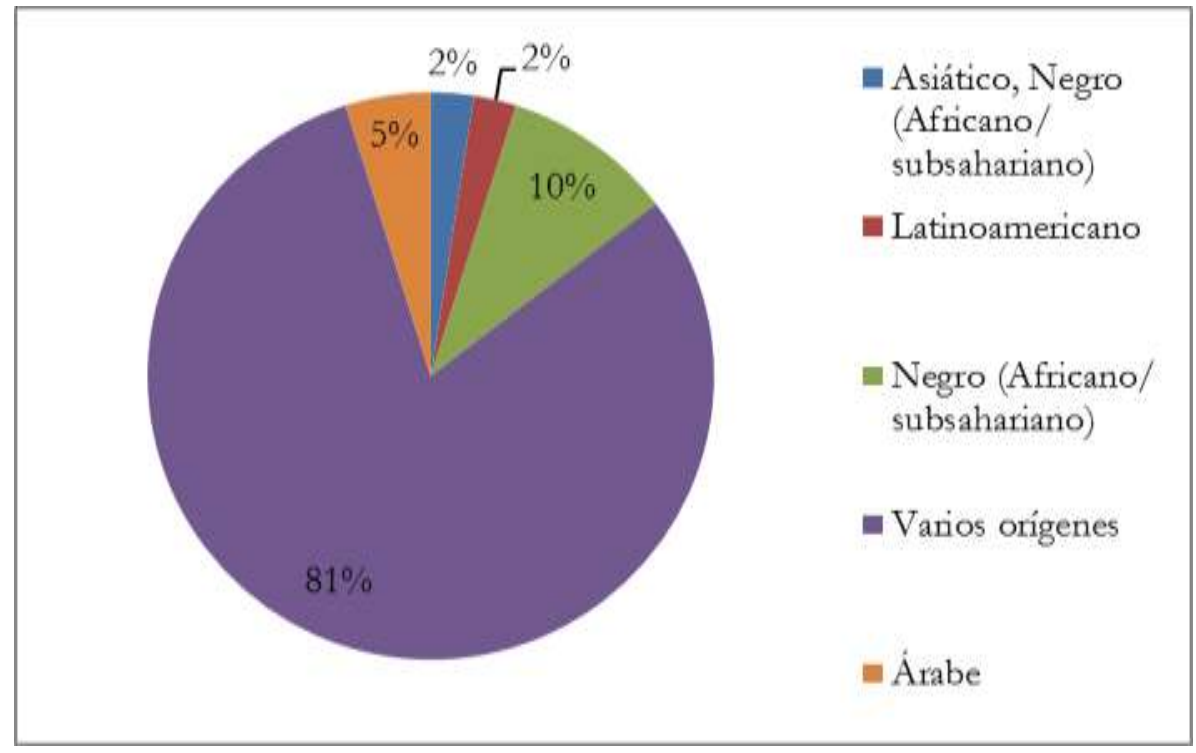

Fuente: Elaboración propia

En relación con el origen, se analiza también la caracterización de los inmigrantes en las imágenes, es decir, los elementos con los que aparecen representados (ropa, peinado, accesorios, contexto). Así se encuentra, en relación con la representación mayoritaria de inmigrantes de varios orígenes en las imágenes, una caracterización multicultural en 22 de los 41 materiales que representan inmigrantes (un $54 \%$ ). Le sigue por orden de importancia, las caracterizaciones occidentalizadas/neutras (18 materiales, un 44\%), en las que se encuentra un uso mayoritario de elementos de la cultura autóctona para la representación de los mismos. 
Gráfico 14. Caracterización de los inmigrantes

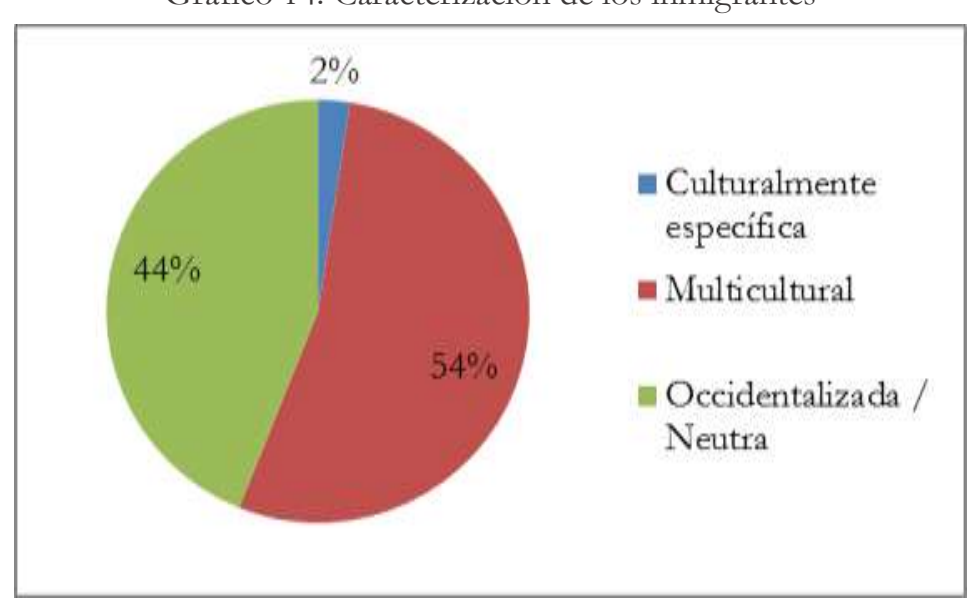

Fuente: Elaboración propia

Por último, respecto al papel y rol del inmigrante en los materiales analizados, se encuentra, que el papel es inexistente en 30 materiales (73\%). Cuando se le otorga un papel en la acción, este es en la mayoría de las ocasiones activo ( 8 materiales, un $20 \%$ ), lo que resulta coherente con la coincidencia del inmigrante con el personaje principal.

Gráfico 15. Papel del inmigrante representado

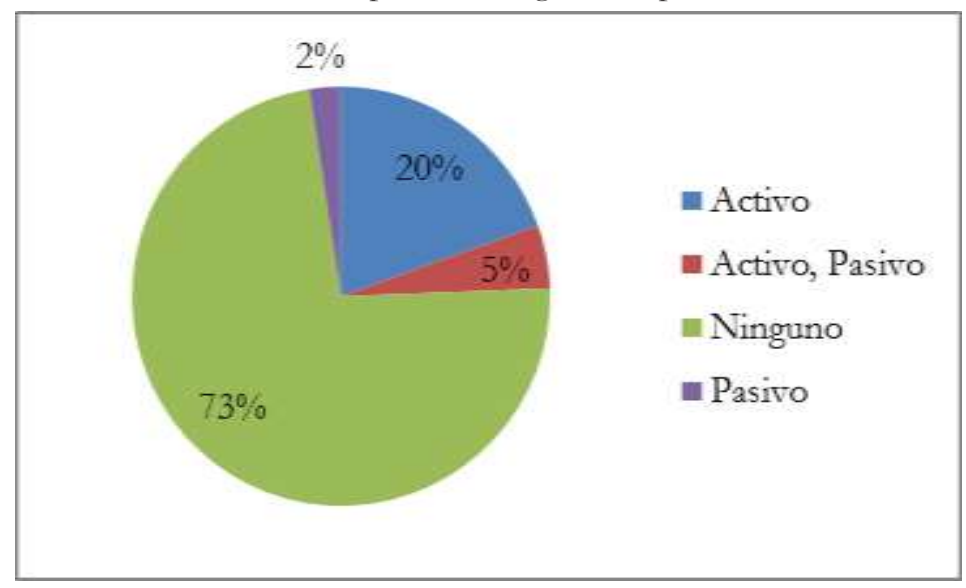

Fuente: Elaboración propia

Estos resultados se relacionan con el recurso a la imagen del inmigrante como representante del público objetivo, lo que se identifica en el total de los materiales que representan algún inmigrante, como muestra la siguiente gráfica. 
Gráfico 16. Rol desempeñado por los inmigrantes representados

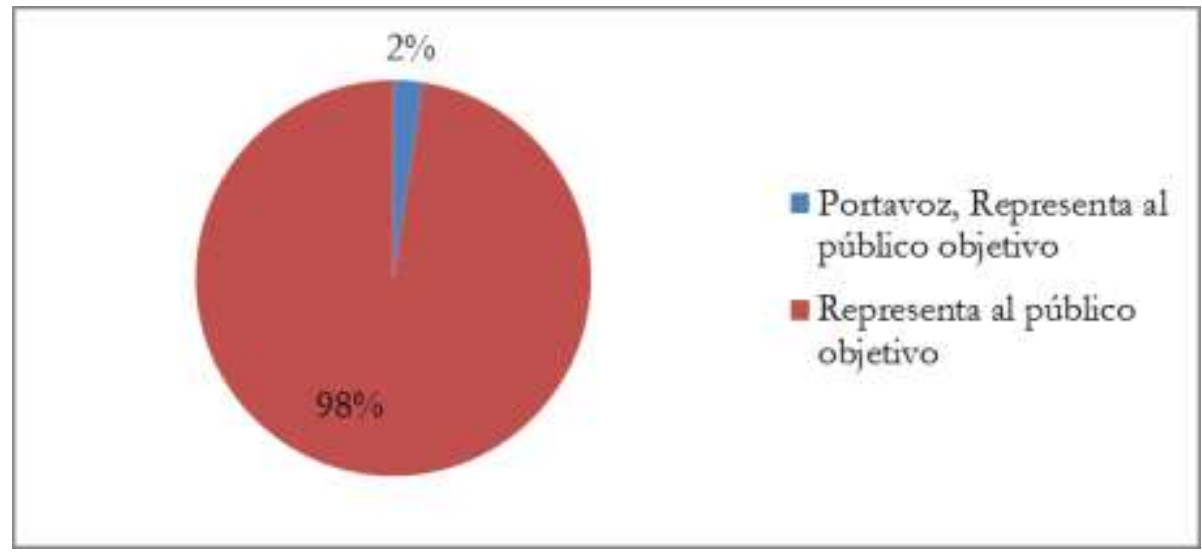

Fuente: Elaboración propia

\subsection{Estereotipos}

Respecto al recurso al estereotipo en los materiales analizados, se encuentran 19 materiales (12\%) que recurren al mismo, frente a $136(88 \%)$ que no lo hacen.

Gráfico 17. Existencia de estereotipos

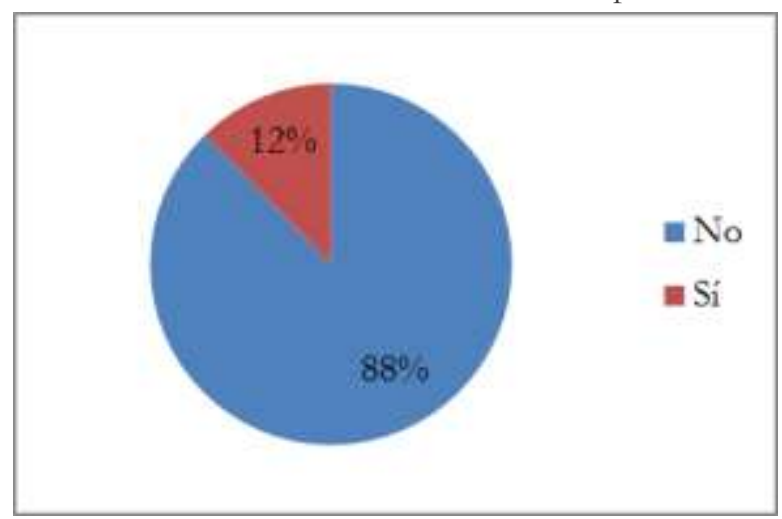

Fuente: Elaboración propia

Cuando se identifican, en la mayoría de las ocasiones (17, un 90\%) se produce en la imagen. De estas, en una ocasión se identifica en imagen y texto. En una ocasión se localiza en el texto. 
Gráfico 18. Forma de representación (imagen/texto) del estereotipo

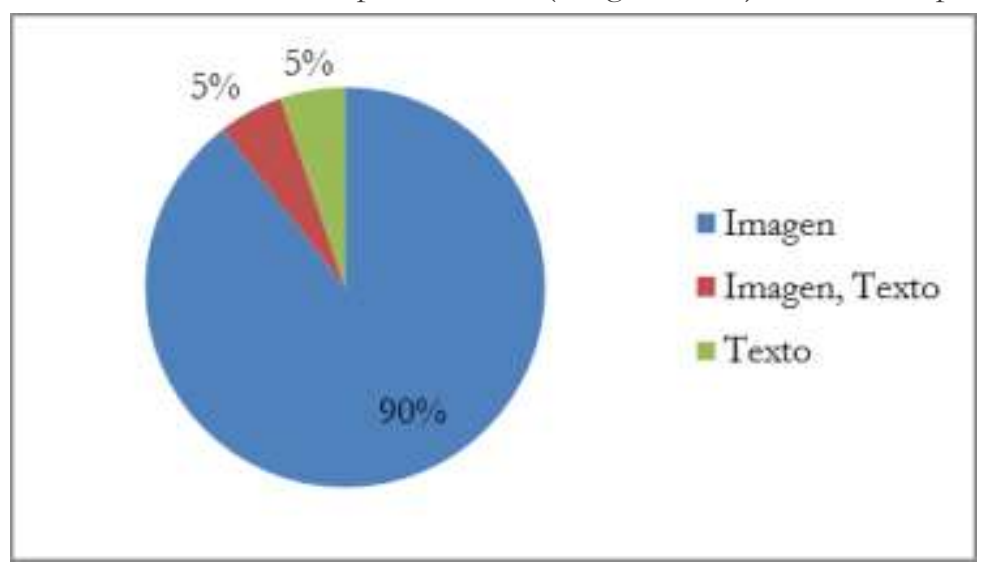

Fuente: Elaboración propia

La referencia del estereotipo es en la totalidad de las ocasiones al receptor, aunque en 7 ocasiones (37\%) se realiza en combinación con otros elementos: acción o contexto, como se muestra a continuación.

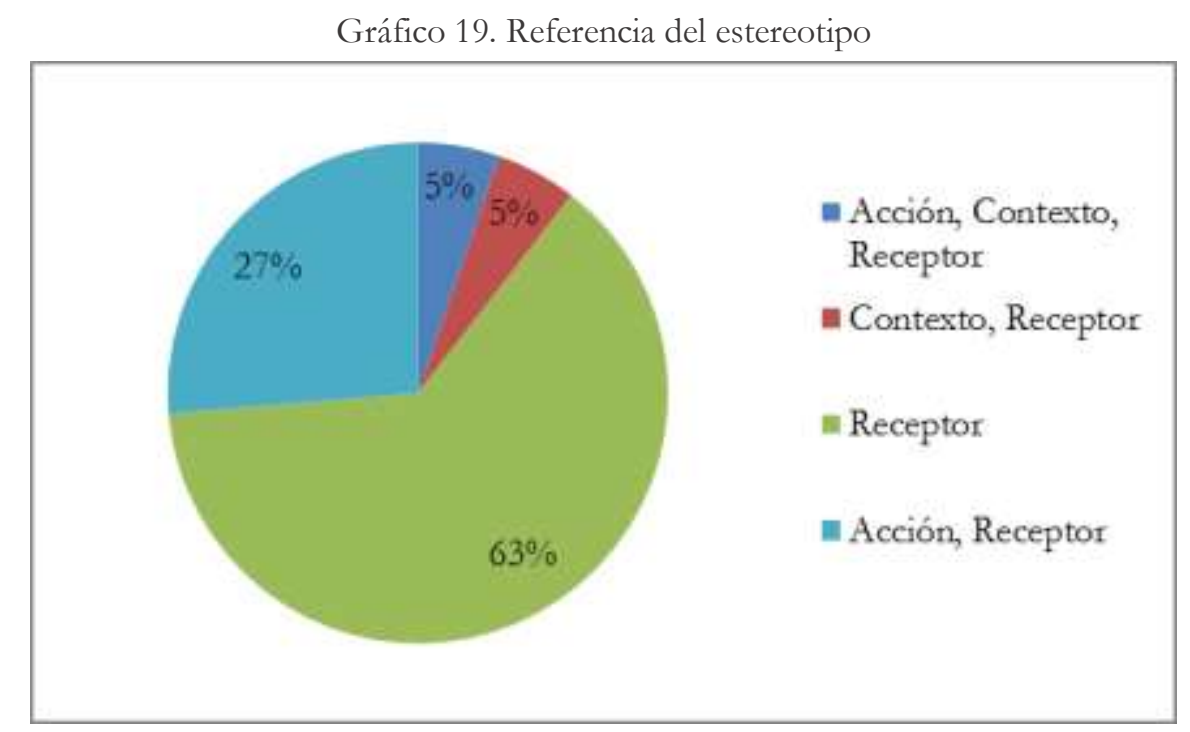

Fuente: Elaboración propia

De hecho, en la variable de descripción de los estereotipos se encuentra fundamentalmente dos estereotipos recurrentes:

- la del trabajador hombre

- la de persona con rasgos negro-africanos como representante de la diversidad cultural

Por tanto, cabría relacionar estos resultados con la caracterización de los inmigrantes en las imágenes, en la que se encuentra la representación de personas inmigrantes con rasgos negro-africanos. 


\section{Discusión}

Se expone a continuación la discusión y reflexiones sobre los resultados del análisis de contenido de las campañas y materiales, organizadas según las variables y las dimensiones analizadas. Se pretende, así, reflexionar sobre las relaciones de los resultados con la situación socio-sanitaria de los inmigrantes en España, así como comparar los resultados con resultados previos de otros autores. El análisis y discusión sobre las variables determinará en último término, la verificación o no de la hipótesis.

Cabe recordar que el protocolo de análisis propio se organizó en tres grandes categorías (personajes, inmigrantes y estereotipos representados), que son las que se exponen a continuación.

\subsection{Personajes}

El análisis de los personajes reveló una preferencia por la representación de personas frente a otro tipo de elementos en los materiales. Respecto al análisis de las características concretas de los personajes representados, se encuentra que estos eran en la mayoría de las ocasiones de ambos géneros, aunque se encuentran también la particularidad de encontrar materiales que representaban exclusivamente mujeres de manera más frecuente que los que representaban exclusivamente a hombres.

Este análisis podría estar en relación con el hecho de haber identificado a la mujer, y sobre todo la mujer inmigrante, como grupo especialmente vulnerable (por ejemplo, por Aerny Perreten et al., 2010). Liu et al. (2012: 60) también encontraron, en su revisión de intervenciones culturalmente adaptadas, que el recurso a la mujer como figura central en el cambio de comportamiento y como agente de cambio por su papel central en las familias era frecuente en las intervenciones adaptadas, frente aquellas dirigidas a la población general.

Por otra parte, en lo que se refiere a la edad, se encuentran sobre todo personajes jóvenes y adultos, lo que es coherente con la curva de edad de los inmigrantes en España. Al examinar la distribución por edad de la población extranjera en España, se observa que esta era mucho más joven que la española en todo el período estudiado, siendo en general el grupo más numeroso el que aglutina personas entre los 25 y los 44 años y, en concreto, entre los 30 y los 34 años (INE, 2015). Entre las explicaciones que se han dado a este fenómeno destacan aquellas que señalan que en general, los jóvenes que llegan de países menos desarrollados vienen en busca de trabajo y mejores condiciones de vida (Reher et al., 2008: 136137).

Lo mismo ocurre con las profesiones representadas. Se identifica que estas son en la inmensa mayoría de las ocasiones relacionadas con trabajos físicos, lo que también se encuentra estar en relación con la situación socio-laboral de los inmigrantes en España, que concentraron su ocupación en trabajos manuales y de escasa cualificación (Reher et al., 2008: 136-137). En ocasiones, se encuentran materiales en los que se representan profesiones de distintas categorías, ampliando el abanico de personas a las que 
apela el material. No obstante, cabe señalar que en la inmensa mayoría de las ocasiones no se identificaba ninguna profesión.

En lo que se refiere al origen de las personas representadas en las imágenes, se identifican, de manera significativa, que en la mayoría de las ocasiones se representa un grupo culturalmente diverso, mientras que la apelación a un colectivo específico es poco frecuente.

Este análisis guarda estrecha relación con el realizado sobre otra de las variables incluidas, y que se refería a la caracterización de los personajes en la imagen. Cabe destacar que en la mayoría de las ocasiones la caracterización de los personajes es occidentalizada o neutra, puesto que se utilizan elementos de la cultura autóctona para su representación (vestimenta, peinados, etc.). La caracterización multicultural se encontró en imágenes en las que se recurría a elementos de diversas culturas para representar lo diverso de su imagen. Se muestra, a continuación, ejemplos en este sentido.

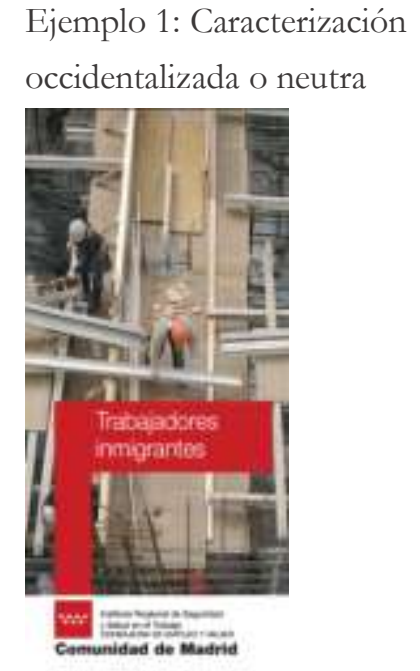

Responsable: Comunidad de Madrid. Año 2006.

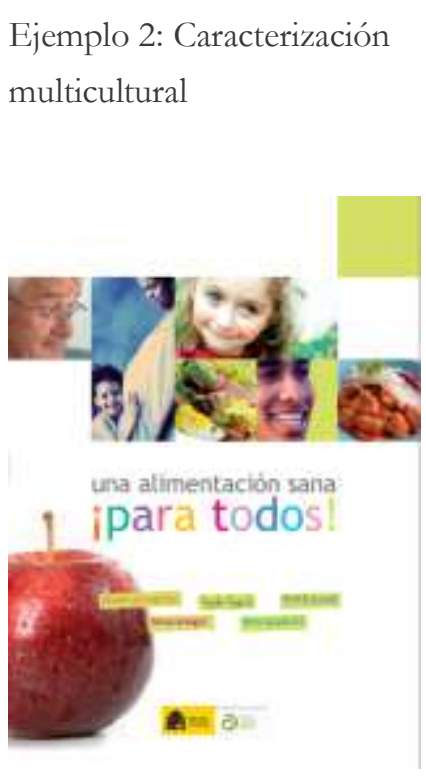

Responsable: Ministerio de

Sanidad. Año 2008.

\section{Ejemplo 3: Caracterización \\ culturalmente específica}

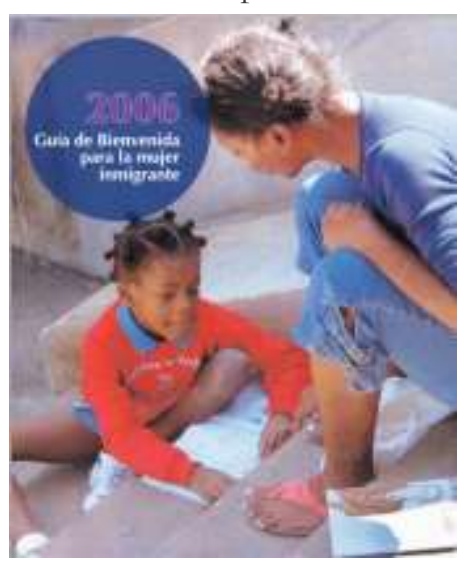

Responsable: Govern de les Illes Balears. Año 2006.

Como puede observarse, la caracterización de los personajes en la primera imagen se realiza con elementos occidentales o neutros, pues se identifican únicamente los elementos necesarios para la preservar la seguridad en el trabajo, y no aquellos representativos de una cultura específica. En la segunda imagen, se observa el recurso a elementos de una diversidad de culturas, en concreto, se recurre a las características físicas los personajes, como su color de piel, como forma de caracterización y diferenciación de los personajes. El último de los ejemplos que se acaban de mostrar recurre a la caracterización propia de una única cultura y no varias, en contra del anterior, y representa personas caracterizadas de forma homogénea y no diversa (recurre a un único estilo de peinado, por ejemplo). 
Por último, respecto al papel y rol de los personajes principales en la imagen, se encuentran que, en línea con el recurso al personaje principal exclusivamente como forma de representación del público objetivo, el rol otorgado a los personajes es en la mayoría de las ocasiones inexistente. Cuando se otorga algún rol al personaje principal, este suele ser el activo, puesto que desempeña la acción representada. Se muestran, a continuación dos ejemplos en este sentido.

Ejemplo 4: Papel: ninguno, rol: representación del público objetivo

Ejemplo 5: Papel: activo, rol: parte del escenario

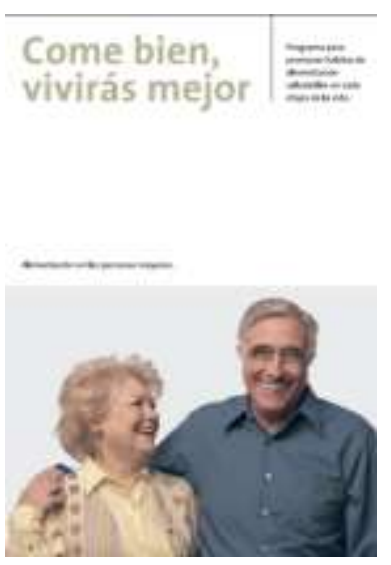

Responsable: Gobierno de Aragón. Año 2001.

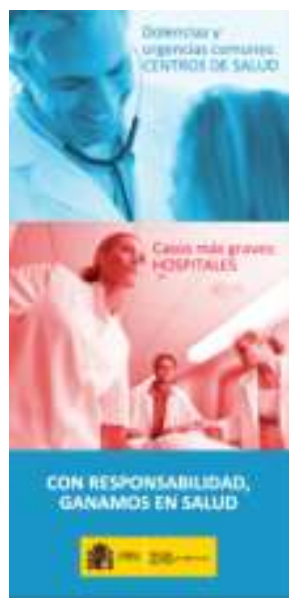

Responsable: Ministerio de Sanidad. Año 2010.

Como puede observarse, los personajes de los ejemplos que se acaban de señalar desempeñan papeles y roles distintos. En el primero, los personajes no realizan ninguna acción, sino que se incluyen en la imagen únicamente con la función de representar al público objetivo del material, en este caso, personas mayores. En el segundo ejemplo, por el contrario, los personajes sí se encuentran realizando una acción. Además, no se incluyen como forma de representación del público objetivo del material (que en este caso no son los profesionales de salud, sino el público en general), sino que forman parte de los escenarios representados en la imagen: una sala de atención primaria, y una sala de urgencias.

Cabe destacar aquí las contribuciones de algunos autores, entre ellos Frankish et al. (1999: 45) en relación con la teoría del aprendizaje social, y que destacaron el aprendizaje mediante la observación de los demás (modelling) como mediadora en el cambio de comportamiento. Existen, por tanto, ciertos apoyos teóricos que nos permitirían apoyar el uso de los personajes como modelos de cambio de comportamiento en los materiales, más allá del uso como representantes del público objetivo o como parte del escenario en las acciones.

\subsection{Inmigrantes}

Es interesante comparar los resultados del análisis de los personajes con el análisis específico de los inmigrantes representados. Así, resulta relevante destacar que aunque se encuentra una mayoría de materiales que representan algún personaje, en la mayoría de las ocasiones los personajes incluidos no representan personas de origen extranjero. Así, se encuentra, que en la mayoría de materiales no se 
representa ningún inmigrante. Este dato contradice, a priori, las recomendaciones de algunos autores que han insistido en la necesidad de la adaptación del elemento visual como forma para conectar con el público objetivo (Masset 1996: 240, Guidry et al. 1999: 296).

No obstante, es cierto que cuando se identifican representaciones de personas inmigrantes, estas coinciden en la inmensa mayoría de las ocasiones con el personaje principal del material, lo que sí resulta un dato a favor de la adaptación cultural de algunos de los materiales.

Respecto a las características de los inmigrantes representados en las imágenes se encuentran, en línea con los resultados del análisis del total de personajes representados, que la mayoría de los materiales representan inmigrantes de ambos géneros y que cuando se representa un género de manera individualizada, abundan los materiales que representan personas de género femenino sobre los que representan únicamente inmigrantes de género masculino.

Este análisis podría estar en relación con el hecho de haber identificado a la mujer, y sobre todo la mujer inmigrante, como grupo especialmente vulnerable (por ejemplo, por AernyPerreten et al., 2010). Ya se había señalado, también, que Liu et al. (2012: 60) encontraron asimismo en su revisión de intervenciones culturalmente adaptadas, que el recurso a la mujer como figura central en el cambio de comportamiento y como agente de cambio por su papel central en las familias era frecuente en las intervenciones adaptadas, frente aquellas dirigidas a la población general.

En cuanto a las edades representadas, destacan, de nuevo, los inmigrantes jóvenes y adultos. Ya se había señalado que esta característica es coherente con la estadística de los inmigrantes en España, y además se destacan que una de las razones por las que ocurre este fenómeno es precisamente que son personas jóvenes las que llegan de países menos desarrollados en busca de trabajo y mejores condiciones de vida.

No obstante, existe un número interesante de materiales que representan inmigrantes de todas las edades. Esta característica se intuye que puede deberse a la probable apelación a la diversidad que se encuentran asimismo en algunos materiales.

En lo que se refiere a las profesiones representadas, se destaca, nuevamente, un amplio número de materiales entre los que no es posible identificar ninguna profesión. Entre los materiales en los que sí es posible, se encuentra una representación mayoritaria de trabajos físicos. Como se ha dicho anterioremente, estas características son coherentes con el análisis previo de los personajes y, además, se relaciona también con la edad de los inmigrantes en España, puesto que se ha deducido que los jóvenes que llegan de países menos desarrollados vienen en busca de trabajo y mejores condiciones de vida y se incorporan al mercado laboral en las actividades que requieren menor cualificación: la agricultura, la construcción, el servicio doméstico y la hostelería.

Análisis individualizado merece, no obstante, la variable origen de los inmigrantes representados. Cabe recordar que aunque en el análisis de esta variable se volvió a encontrar que la mayoría de los materiales 
representaban inmigrantes de varios orígenes, cuando se representaba un origen único, la representación mayoritaria era la de personas con rasgos negro-africanos. Esta representación contrasta con los orígenes mayoritarios de inmigrantes en España, que se receurda procedían del Este de Europa (principalmente Rumanía) y Norte de África (fundamentalmente Marruecos) y se relaciona, más adelante, con el recurso al estereotipo en los materiales analizados.

Además, estos hallazgos parecen demostrar el recurso en estos materiales, como en otro tipo de campañas, a la apelación a la diversidad. Se entiende que el recurso a este tipo de representaciones responde más a un interés de la Administración de apelar a la diversidad que de realmente segmentar la audiencia en grupos significativos desde el punto de vista de la comunicación para la salud.

En este sentido, cabría preguntarse si cuando se trata de cuestiones relacionadas con la comunicación en salud, la apelación a la diversidad es el marco más apropiado. Padilla y Pereira (2009: 16) recordaban que existen necesidades específicas y que estas requieren respuestas personalizadas. Se cree conveniente, por tanto, destacar el ámbito de mejora existente en este sentido. A continuación se muestran dos ejemplos característicos de apelación a la diversidad y a colectivos más específicos.

Ejemplo 6: Material que apela a la diversidad

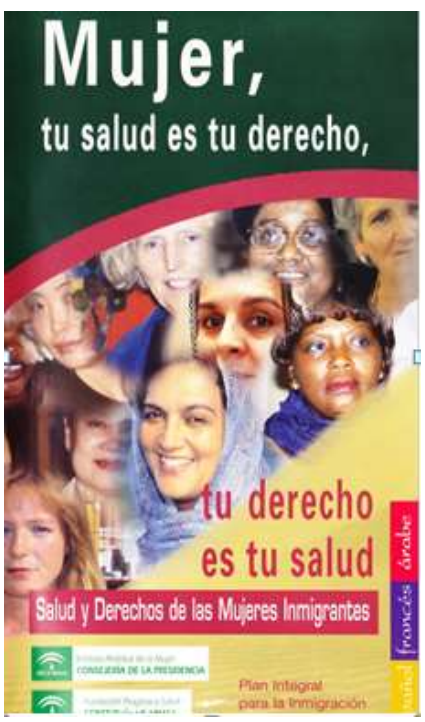

Responsable: Junta de Andalucía. Año 2002.

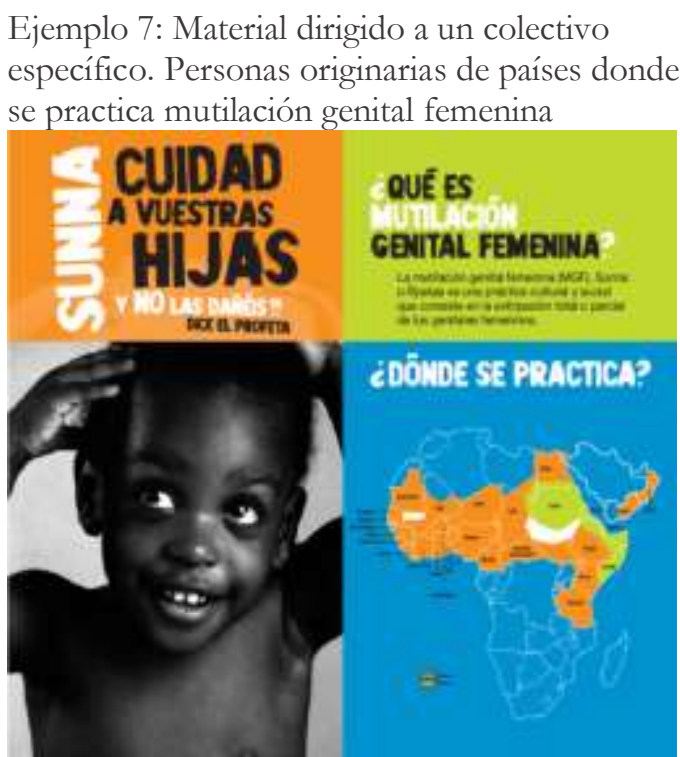

Responsable: Generalitat de Catalunya.

Año 2006

Como puede observarse, la primera imagen realiza una apelación a la diversidad en tanto en cuanto conforma su escena con mujeres que se deducen de orígenes distintos. Por el contrario, la segunda imagen ancla a través de la imagen de su personaje y del mapa, los orígenes concretos a los que se dirige el material, en este caso, a aquellas personas originarias de países donde se practica la mutilación genital femenina. 
Estos ejemplos, son además, representativos del análisis de la variable caracterización de los inmigrantes en las imágenes (es decir, los elementos con los que aparecen representados: ropa, peinado, accesorios, contexto). Se recuerda que cuando se identifica una caracterización distinta a la autóctona, esta era en la mayoría de las ocasiones multicultural, es decir, se utilizaban elementos de varias culturas en la representación (como muestra el ejemplo 6). Este hallazgo es coherente con la representación mayoritaria de inmigrantes de varios orígenes en las imágenes y con la idea destacada de apelación a la diversidad.

Se cree conveniente, por tanto, remitir a las recomendaciones previas de otros autores de adaptar el elemento visual, imágenes y fotografías en los materiales dirigidos a minorías (Masset 1996: 240, Guidry et al. 1999: 296). Weintraub et al. (2003: 279), por ejemplo, señalaron específicamente que las imágenes deberían mostrar personas similares al público objetivo para alcanzar un mayor grado de adaptación; y que revisiones muy recientes, como la de Liu et al. (2012: 91) incluyeron la utilización de personajes similares al público objetivo como una tipología de adaptación fundamental en las intervenciones.

Por último, respecto al rol y papel del inmigrante en los materiales analizados, se vuelve, de nuevo, a remitir a la contribución de Frankish et al., (1999: 45) en relación con la teoría del aprendizaje social, que destacaron el aprendizaje mediante la observación de los demás (modelling) como mediadora en el cambio de comportamiento. En este sentido, cabría cuestionarse el escaso papel activo de los inmigrantes en los materiales analizados.

\subsection{Estereotipos}

Por último, respecto al recurso al estereotipo en los materiales analizados, se encuentra una minoría de materiales que recurre al mismo como forma de representación del receptor. Se relacionan, por tanto, estos resultados con la caracterización de los inmigrantes en las imágenes, en la que se encuentra una significativa representación de personas inmigrantes con rasgos negroafricanos. De hecho, en la variable de descripción de los estereotipos se encuentran fundamentalmente dos estereotipos recurrentes:

- El de "trabajador hombre".

- El de persona con rasgos negro-africanos como representante de la diversidad cultural

No siendo el objetivo de este trabajo ahondar en cuestiones relacionadas con el uso y abuso del estereotipo, sí conviene señalar que el recurso al mismo podría responder a la función de la comunicación de servir a la labor de reproducción social y a la vez facilitar la identificación y memorización de ideas fundamentales.

Es uso y abuso del estereotipo en comunicación, y más concretamente en publicidad, ha sido objeto de estudio de numerosos autores. Cabría destacar los trabajos de Izquierdo (2004), sobre la representación de la raza en publicidad; Galán Fajardo (2006), sobre la representación de los inmigrantes en la ficción televisiva en España; y Gaona Pisonero y Martínez Pastor (2008) sobre 
los estereotipos étnicos empleados para la caracterización de los inmigrantes en la Publicidad Institucional, entre otros.

Gaona Pisonero y Martínez Pastor (2008: 364), por ejemplo, señalaron que:

"El uso y la presencia de los estereotipos en los discursos de los medios de comunicación es una constante en los mismos, y es también un hecho extrapolable a la publicidad institucional de las Administraciones Públicas. Nuestro posicionamiento no se inserta en una crítica del uso de los estereotipos, no se defiende un derribo absoluto de los estereotipos, éstos al igual que los marcos metacomunicativos de Bateson, o los marcos de Goffman nos ayudan a elaborar la inteligibilidad y la normalidad de las situaciones comunicativas, y en general de las situaciones sociales. Lo que se plantea es una concienciación acerca de los abusos del uso de los estereotipos. Ahí radica el auténtico peligro de los estereotipos, pues desde ese abuso se posibilita muchas veces una fácil interpretación del mundo cotidiano tanto para legitimar nuestra conducta, como para la legitimización de la cultura hegemónica" (Gaona Pisonero y Martínez Pastor, 2008: 364).

Por tanto, no se denuncia el uso del estereotipo, sino una necesaria reflexión en el sentido del recurso al mismo como forma de legitimación de nuestra propia cultura, la cultura dominante, sobre las otras.

En sus investigaciones, Gaona Pisonero y Martínez Pastor encontraron a los inmigrantes como protagonistas absolutos de las campañas de la Publicidad Institucional de las Administraciones Públicas; pues analizaban un tipo de Publicidad Institucional muy específica que ellas centraron en el "marketing de la diversidad". En este tipo de campañas las autoras resaltaron los estereotipos que contribuían a reafirmar las ideaciones sobre la positividad de la diversidad cultural, los beneficios de una sociedad intercultural, y hasta la existencia de una sociedad multicultural. Por tanto, se encuentran, efectivamente, un recurso al estereotipo, en fin, con objetivos posiblemente positivos (Gaona Pisonero y Martínez Pastor, 2008: 365).

Resaltaron, por ejemplo, el recurso al atractivo estético de la diversidad, y a la presentación de un prototipo de "inmigrante ideal" (Gaona Pisonero y Martínez Pastor, 2008: 365). Estos estereotipos pueden verse en algunos materiales aquí analizados como el que se muestra a continuación, en el que se representan dos personajes con características negro-africanas y asiáticas como forma de idealización de la diversidad.

Ejemplo 8: Recurso al estereotipo como forma de representación del "atractivo" de la diversidad y el "inmigrante ideal" 


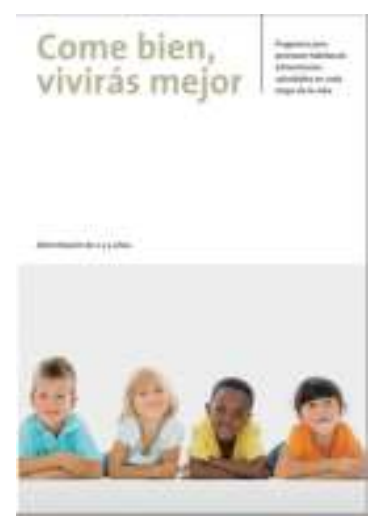

Responsable: Gobierno de Aragón. Año 2004.

Cabe concluir, una vez analizadas las variables planteadas, que se corrobora la hipótesis de partida al constatar, en definitiva, que las campañas y materiales de Comunicación Institucional para la Salud dirigidas a inmigrantes no incluyen de manera generalizada representaciones de personas de una diversidad de orígenes.

Es cierto que los resultados de este trabajo resultan limitados en tanto en cuanto la adaptación cultural de materiales se juzga en relación con las variables analizadas, únicamente, y basándonos en las versiones en español de los materiales, exclusivamente. Existen otra serie de variables que podrían analizarse, tales como la calidad de las traducciones o la legibilidad de los textos, para enriquecer el análisis de la adaptación cultural de los materiales más allá de la adaptación de las imágenes y, en concreto, de la representación de los personajes e inmigrantes en las mismas.

Además, se coincide con otros autores, entre ellos Weintraub et al. (2003: 279) en señalar que este tipo de análisis de la adaptación cultural se complementaría muy adecuadamente con la inclusión de la población objetivo en los análisis, en especial con la organización de focusgroup y/o entrevistas en profundidad, lo que supone una sugerencia para investigaciones futuras.

\section{Conclusiones}

De todo lo anterior, se deduce que el análisis específico de las personas e inmigrantes representados en los materiales demostró que a pesar de existir materiales en los que se recurre a la imagen como forma de representación del público objetivo, realmente se encontró un punto débil en la adaptación cultural de materiales al observar que no se aprovechan las imágenes reales de personas para representar a personas o elementos de una diversidad de orígenes, tal y como se ha demandado.

No obstante, entre los materiales que representan al inmigrante en sus imágenes, sí se encuentra cierta coherencia en género, edad y profesión con las características identificadas a nivel sociosanitario, aunque se cuestiona el escaso papel activo de los inmigrantes en las imágenes encontradas en los materiales analizados, y se constata la existencia del recurso al estereotipo en algunos de los mismos. 
Aunque el recurso al estereotipo no fue mayoritario, sí se encuentran algunas representaciones de personas con rasgos negro-africanos como representantes de la diversidad cultural. En este sentido, se señala una necesaria reflexión sobre el posible abuso de los mismos, pues aunque pueden facilitar la interpretación de los elementos comunicativos, en definitiva podrían estar contribuyendo a perpetuar los usos y abusos de la cultura hegemónica.

Se concluye, en definitiva, que las campañas y materiales de Comunicación Institucional para la Salud dirigidos a inmigrantes analizados no adaptan culturalmente sus imágenes.

De hecho, como elemento fundamental en el análisis, se desetaca que la representación del inmigrante en la imagen es minoritaria y, cuando ocurre, se realiza de manera genérica, representando grupos culturalmente diversos.

Para finalizar, cabe señalar, que pese a lo incipiente de esta investigación, se trata de la primera y única investigación que ha propuesto analizar la adaptación cultural de los materiales para la salud editados por las Administraciones Públicas en nuestro país. En este sentido, supone un importante avance en el interés por sistematizar la evaluación de la Comunicación Institucional Intercultural para la Salud (CIIS) que se lleva cabo en España.

\section{Bibliografía}

AERNY-PERRETEN, N. et al. (2010). "La salud y sus determinantes en la población inmigrante de la Comunidad de Madrid”. Gaceta Sanitaria [en línea]. Vol. 24, núm. 2, p.136-1442. [Último acceso 1 de octubre de 2015]. Disponible en: http://scielo.isciii.es/pdf/gs/v24n2/original8.pdf

ALSINA, M.R. (1997). "Elementos para una comunicación intercultural". Revista Cidobd'AfersInternacionals. Núm. 36, p. 11-21.

ARROYO, I. (2009). Creatividad e investigación en la publicidad dirigida al colectivo inmigrante: la senda de la integración.Comunicación y Hombre. Vol. 1, Núm. 5. P. 119-128.

BALADRÓN, A.J. (2009) Consumo y publicidad para inmigrantes: claves para dirigirse a un mercado emergente. A Coruña: Netbiblo. 272p.

BARDIN, L. (1996) El análisis de contenido. 2a ed. Madrid, Akal. 183 p.

BERKMAN N.D.; DEWALT D.A.; PIGNONE M.P.; SHERIDAN S.L.; LOHR K.N.; LUX L., SUTTON S.F.; SWINSON T.; BONITO A.J. (2004). Literacy and Health Outcomes.Summary, Evidence Report/Technology Assessment No. 87. AHRQ Publication No. 04-E007- 1 [enlínea]. Rockville, MD: Agency for Healthcare Research and Quality. [Último acceso 1 de octubre de 2015]. 
Disponible

http://archive.ahrq.gov/downloads/pub/evidence/pdf/literacy/literacy.pdf

BORRELL, C.; DÍEZ, E.; MORRISON, J.; CAMPRUBÍ, L. (2012). Las desigualdades en salud a nivel urbano y las medidas efectivas para reducirlas [en línea]. Barcelona: Proyectos Medea e IneqCities. 2012. [Último acceso 1 de octubre de 2015]. Disponible en: http://www.aspb.cat/quefem/docs/equidad_salud_urbana.pdf

CORTÉS GONZÁLEZ, A. (2011). "La publicidad institucional en España. Una década en perspectiva". Razón y palabra. Núm. 75, ISSN-e 1605-4806

CUESTA, U.; UGARTE, A. y MENÉDEZ, T. (2006). Comunicación Social y Salud. UnaIntroducción. Madrid: Edipo.

FRANKISH, C.J., LOVATO, C.Y., Y SHANNON, W.J. (1999). "Models, theories, and principles of health promotion with multicultural populations".En: Huff, R.M. y Kline, M.V. (Eds.). Promoting Health in MulticulturalPopulations: A Handbook for Practitioners.UnitedStates: SAGE Publications. p.64-100.

GALÁN FAJARDO, E. (2006). "La representación de los inmigrantes en la ficción televisiva en España. Propuesta para un análisis de contenido. El Comisario y Hospital Central”. Revista Latina de Comunicación Social [en línea]. Núm. 61. [Último acceso 1 de octure de 2015], Disponible en: http://www.ull.es/publicaciones/latina/200608galan.ht

GAONA PISONERO, C. y MARTÍNEZ PASTOR, E. (2008). "La presencia Étnica en la Publicidad Institucional”. IC Revista Científica de Información y Comunicación.Núm.5, p. 326-374. ISSN 1696-2508

GARCÍA LÓPEZ, M. (2001). Publicidad institucional: el estado anunciante. España: Universidad de Málaga (UMA). ISBN 84-7496-908-5

GUIDRY, J.J.; LARKE, P.; WALKER, V.D.; FAGAN, P.; MCDOWELL, T.; CORMEAUX, S. (1996). Cancer prevention materials for African-Americans: cultural sensitivity assessment tool manual [enlínea]. Disponible en: http://www.texascancer.info/pcemat/titlepage.html

INE. Demografía $y$ población [en línea]. Disponible en: http://www.ine.es/inebmenu/mnu cifraspob.htm. [Consulta: 01 de marzo de 2015]

IZQUIERDO IRANZO, P. (2004). Representación de la raza en la publicidad: análisis de 'El País Semanal, 1997-2003. Tesis leída en la Universidad Complutense de Madrid. 
LIU, J.; DAVISON, E.; BHOPAL, R.; WHITE, M.; JOHNSON, M.; NETTO, G.; DEVERILL M., SHEIKH A. (2012).“Adapting health promotion interventions to meet the needs of ethnic minority groups: mixed-methods evidence synthesis". HealthTechnologyAssessessment. Vol 16, núm 44.

MARTÍNEZ NICOLÁS, M. (2009). "La investigación sobre comunicación en España. Evolución histórica y retos actuales". Revista Latina de Comunicación Social [en línea]. Núm. 64, p.114. Disponible en: http://www.revistalatinacs.org/09/art/01_800_01_investigacion/Manuel_Martínez_ Nicolás.html

MARTÍNEZ PASTOR, E. (2009). "Interculturalidad de la administración pública a través de las campañas institucionales de publicidad en materia de inmigración” [en línea]. En: La dinámica del contacto. Movilidad, encuentro y conflicto en las relaciones interculturales. II Training Seminar de jóvenes investigadores en Dinámicas Interulturales. Panel III. Movilidad, participación y políticas públicas: La inmigración comodinamizador politico e institucional. Disponible en: http://www.cidob.org/media2/publicacions/monografias/ii_doctorandos/15_martinez

MARTÍNEZ PASTOR, E. y VIZCAÍNO-LAORGA, R. (2008). "Publicidad institucional como fenómeno integrador ante la inmigración en España: régimen jurídico". Revista Latina de Comunicación Social. Núm. 63, p. 90-98.

MARTÍNEZ PASTOR, E.; GAONA PISONERO, C. y VIZCAÍNO-LAORGA, R.(2008). Comunicación Institucional Intercultural. Los CEPI, una iniciativa de la Comunidad de Madrid. Madrid: Observatorio de las Realidades Sociales y de la Comunicación.

MASSETT, H.A. 1996. "Appropriateness of Hispanic print materials: a content analysis". HealthEducationResearch. Vol 11, núm 2. p. 231-242.

MINISTERIO DE SANIDAD Y CONSUMO. (2001). Infección por VIH y sida. Plan multisectorial 2001-2005. Madrid: Ministerio de Sanidad y Consumo.

_ (2008). Plan multisectorial frente a la infección por el VIH y el sida 2008-2012. Madrid: Ministerio de Sanidad y Consumo.

MINISTERIO DE SANIDAD, SERVICIOS SOCIALES E IGUALDAD. (2012). Sistema Nacional de Salud [en línea]. Madrid: Ministerio de Sanidad, Servicios Sociales e Igualdad. [Ultimo acceso 1 de octubre de 2015]. Disponible en: http://www.msssi.gob.es/organizacion/sns/docs/sns2012/SNS012.pdf 
PADILLA, B. y PEREIRA, J.M. (2009). "Health and Migration in the European Union: Building a Shared Vision for Action". En: Padilla, B. y Pereira, J.M. (Eds.). Health and Migration in the European Union: Better Health for All in an Inclusive Society [enlínea].Lisboa: Instituto Nacional de SaúdeDoutor Ricardo Jorge. [Último acceso 15 de octubre de 2015] Disponible en: http://www.insa.pt/sites/INSA/Portugues/Publicacoes/Outros/Documents/Epidemiologia/H ealthMigrationEU2.pdf

PIÑUEL RAIGADA, J.L. (2002). "Epistemología, metodología y técnicas del análisis de contenido". Estudios de Sociolingüística. Vol. 3, núm. p. 1-42.

REHER,D.S. et. al.(2008). Informe Encuesta Nacional de Inmigrantes (ENI - 2007) [en línea]. Madrid: INE. Documentos de trabajo, 2/08. [Ultimo acceso 1 de octubre de 2015]. Disponible en: www.ine.es/daco/daco42/inmigrantes/informe/eni07 informe.pdf.

SALES SALVADOR, D. (2006). "Mapa de situación de la traducción/interpretación en los servicios públicos y la mediación intercultural en la comunidad valenciana y la región de Murcia". Revista española de lingïistica aplicada (resla). Extra 1, pp: 85-109

U.S. DEPARTMENT OF HEALTH AND HUMAN SERVICES.(2010). HealthyPeople 2020 [en línea]. Washington: U.S. Department of Health and Human Services. [Ultimo acceso 1 de marzo de 2015].Disponible en: http:/ / www.healthypeople.gov/

UGARTE, A. (2011). "Por qué Revista de Comunicación y Salud". Revista de Comunicación y Salud [en línea]. Vol. 1, núm. 1. p. 1-3. [Último acceso 1 de marzo de 2015]. Disponible en: http://www.revistadecomunicacionysalud.org/index.php/rcys

_(2008). "El binomio comunicación y salud: relaciones e investigación”. En: Comunicación y salud: avances en modelos y estrategias de intervención. Madrid: Editorial Complutense. p.39-47.

VALERO, C. (2013). La comunicación en el ámbito médico-sanitario = Communicating in thehealthcaresetting.Alcalá de Henares: Universidad De Alcalá Universidad De Alcalá.

WEINTRAUB, D.; MALISKI, S.L.; FINK, A.; CHOE, S. y LITWIN, M.S. (2004) "Suitability of prostate cancer education materials: applying a standardized assessment tool to currently available materials". Patient Education and Counseling.Vol 55, núm 2, p.275-280.

\section{Notas}

${ }^{1}$ Se adapta para el propósito de este trabajo la diferenciación que propone Alsina (1997: 13) entre multiculturalismo e interculturalidad. Alsina entiende multiculturalismo como "la coexistencia de 
distintas culturas en un mismo espacio real, mediático o virtual" e interculturalidad como "las relaciones que se dan entre las mismas". Es decir, para él, el multiculturalismo "marcaría el estado, la situación de una sociedad plural desde el punto de vista de comunidades culturales con identidades diferenciadas"; mientras que la interculturalidad haría referencia a "la dinámica que se da entre estas comunidades culturales". Así, señala coincidir con Israel (1995: 63) en "que la realidad es multicultural, plural y diversa es un hecho, un punto de partida. Intentar que sea intercultural pasa por el desarrollo de dispositivos comunicativos interculturales", tal y como se propone a lo largo del presente trabajo.

${ }^{2}$ Con Comunicación Institucional se refiere a lo largo de este trabajo a aquella que parte de la Administración Pública, amparándonos en la terminología utilizada por la Ley 29/2005, de 29 de Diciembre, de Publicidad y Comunicación Institucional. 


\section{(c) (1) (2)}

Licencia Creative Commons

Miguel Hernández Communication Journal mhcj.es

Forma de citar este artículo en las bibliografías

Elsa María Moreda Sánchez, Esther Martínez Pastor, Ricardo Vizcaíno Pérez (2016): “ La imagen del inmigrante en materiales de Comunicación Institucional Intercultural para la Salud”, en Miguel Hernández Communication Journal, nº7, páginas 53 a 85. Universidad Miguel Hernández, UMH (Elche-Alicante). Recuperado el__ de de $20 \_$de: $\lfloor$link del artículo en mhjournal.org] 